\title{
HISTORIA Y SOCIOLOGÍA DE LA ADOPCIÓN EN ESPAÑA
}

\author{
PEDRO CASTÓN BOYER y JOSÉ OCÓN DOMINGO \\ Universidad de Granada
}

PALABRAS ClaVe Adicionales

Infancia, Familia, Menores, Servicios Sociales.
ADDITIONAL KEYWORDS

Childhood, Family, Minors, Social Services.

RESUMEN. Con este trabajo pretendemos informar sobre el devenir histórico que, desde el punto de vista jurídico y social, ha experimentado la adopción desde la antigüedad hasta nuestros días. También tratamos de mostrar, de modo detallado, los resultados más relevantes obtenidos en las investigaciones realizadas en España relacionadas con este recurso alternativo de protección de menores. Finalmente, aportamos algunos datos estadísticos publicados hasta la fecha por los organismos oficiales con responsabilidades en materia de infancia, tomando como referente las formalizaciones de la adopción en cada Comunidad Autónoma.

SUMMARY. The aim of this study is to investigate the changing juridical and social aspects of adoption from ancient to modern times. More in detail, we present the main results of investigations carried out in Spain concerning this particular means for the protection of minors. Finally, we bring together some of the statistical information published by official organisms responsible for the care of the young with regard to the formalities of adoption now in force in each autonomous community.

E-mail: pcaston@ugr.es joseocon@ugr.es

Revista Internacional de Sociología (RIS)

Tercera Época, nº 33, Septiembre-Diciembre, 2002, pp. 173-209. 
RIS

REVISTA INTERNACIONAL DE SOCIOLOGIA

№33, Septiembre-Diciembre, 2002

PEDRO CASTÓN BOYER Y JOSÉ OCÓN DOMINCO

\section{INTRODUCCIÓN}

La adopción, como otras instituciones, ha experimentado en función del espacio y del tiempo importantes cambios y modificaciones, según las normas y valores culturales característicos de cada una de las sociedades en las que, como acto jurídico-social, ha aparecido. Frente a ciertas civilizaciones tradicionales que no reconocen la figura adoptiva, como las sustentadas religiosamente en el Islam, nuestra civilización occidental, por el contrario, se ha distinguido por ofrecer algunas modalidades de este recurso como una forma más de atender históricamente a la infancia.

De acuerdo con los estudios realizados, la adopción se muestra como un recurso eficiente para hacer frente al problema de los niños huérfanos, abandonados o con ciertas dificultades sociales. Por ello, junto al acogimiento familiar, esta medida, tanto en su modalidad nacional como internacional, está demostrando su capacidad para colaborar al adecuado desarrollo de la personalidad del menor, frente a las consecuencias perversas que puede producir la vida en masificados internados, aislados del entorno natural y lejos de la figura materna u otros integrantes de la unidad familiar. En efecto, el auge que progresivamente ha ido tomando la adopción, tanto en España como en otros países desarrollados, tiene su fundamento en el conjunto de problemáticas psicosociales y económicas observadas en los niños por algunos autores considerados como clásicos en el tema de la infancia.

Así, R. Spitz (1945) acuñará el término "síndrome de hospitalismo" para hacer referencia a los rasgos negativos que, debido a una atención inadecuada, presentaban en su personalidad los niños internados . Posteriormente, el psiquiatra J. Bowlby en su obra Maternal Care and Mental Health (1951) destacará la incidencia que para el equilibrio psicológico de los niños produce la ausencia de relaciones íntimas y continuadas con la madre, así como los efectos perversos que en el carácter y vida posterior del niño podría ocasionar la estancia prolongada en las instituciones. En todo caso, proponía que se evitara el internamiento de los niños menores de seis ànos $\mathrm{y}$, para aquellos niños con necesidades psiquiátricas con edades comprendidas entre los seis y doce años, recomendaba que la medida se materializase en instituciones pequeñas y siempre atendidos por profesionales con los adecuados conocimientos psicopedagógicos. En esta misma dirección, E. Goffman escribió en 1961 su obra Asylums (Internados, 1988) en la que establece el término "Instituciones Totales" para referirse a las consecuencias que en diferentes áreas (motivación, agresividad, cognición, etc.) pueden resultar del internamiento en instituciones aisladas y bajo un régimen de funcionamiento muy peculiar. Aunque este estudio de campo se centraba en las instituciones psiquiátricas, algunos autores han advertido que sus resultados también podrían aplicarse a los niños debido a su maleabilidad y a la falta de interiorización de los valores y normas de la cultura circundante, que se hace posible a través del contacto con las distintas agencias y agentes de socialización. Pese a estas advertencias, hasta 
el año 1977 no serán abordados los aspectos relacionados con las necesidades psicológicas, afectivas, intelectuales y sociales de los niños por un organismo de relevancia internacional como el Consejo de Europa que, en su Resolución (77) 33 sobre acogimiento de menores, recoge las características que han de reunir los centros de acogida de menores, abogando por otras medidas preventivas y por la intervención de los equipos técnicos apropiados.

En España, si bien con cierto retraso en relación con los países más avanzados de nuestro entorno, a partir de los años setenta se produce una nueva forma de entender la protección de la infancia, que culminará con las posibilidades que proporciona la promulgación de la Constitución española de 1978 y la consiguiente transformación de España en un Estado democrático. A partir de estas fechas se irán favoreciendo, frente al recurso estrella de la institucionalización, otras alternativas políticas de corte más moderno y más respetuosas con los derechơs e intereses de los menores, de acuerdo con la normativa internacional más avanzada'. Como consecuencia, desde la Administración se concibe el internamiento en centros de protección como una medida de carácter provisional y por el tiempo imprescindible, hasta que el menor pueda ser integrado en su unidad familiar de origen o, siempre que sea posible y aconsejable, pueda ser colocado bajo otros recursos alternativos de protección como el acogimiento familiar o la adopción. Esta última medida es oportuna en los casos en que los niños han sido abandonados por los padres, o en aquéllos en que las adversas circunstancias que rodean a los responsables del niño les incapacita de manera permanente para cumplir adecuadamente con los deberes inherentes a la patria potestad, haciendo imposible la reintegración familiar. Esta situación de desamparo en la que queda el menor provoca la intervención de la entidad pública responsable de la protección de menores, asumiendo la tutela del menor y la colocación del niño en el recurso de protección más adecuado para satisfacer sus peculiares necesidades e intereses.

Tomando como referente el criterio del bienestar del menor, en la primera parte de este trabajo realizamos un breve recorrido histórico que nos permita comprender de un modo más amplio y, quizás más profundo, los objetivos e intereses que, en cada una de las etapas históricas, han orientado la práctica del proceso adoptivo en el seno de nuestra civilización occidental. Y, en la segunda parte, pretendemos describir algunas de sus connotaciones actuales, ofreciendo un amplio resumen de los resultados sociológicos aportados por las únicas investigaciones realizadas hasta el momento en España.

'Nos referimos básicamente, en el tema que nos ocupa, a la Convención de las Naciones Unidas sobre los Derechos del Niño de 1989 y al Convenio relativo a la protección del niño y a la cooperación en materia de adopción internacional, aprobado por la conferencia de La Haya de Derecho Internacional Privado, el 29 de Mayo de 1993. 


\section{ALGUNOS ANTECEDENTES HISTÓRICOS}

Aunque somos conscientes que sería muy ilustrativo para el lector la inclusión en este apartado de aquellas circunstancias sociales que en cada una de las distintas etapas históricas han sustentado el hecho adoptivo, este deseo, desde una óptica de la sociología de la infancia o de la familia, se torna en una empresa ciertamente difícil. En efecto, existen algunas fuentes que hacen una alusión muy general a la colocación de los niños bajo distintos recursos, pero con relación a las variables psicosociales que los fundamentan y a las connotaciones del mismo proceso adoptivo tratadas de modo específico, encontramos una notable ausencia. Por ello, quizás desde un abordaje histórico del concepto de infancia, de las relaciones familiares y de las medidas sociales a disposición del menor, pueda deducirse cómo estas dimensiones son, junto a otras circunstancias sociales y económicas, las que han perfilado las características que han venido teniendo la adopción y la frecuencia con que ha sido utilizada.

Si partimos de la Edad Media, observamos cómo el niño era considerado como una propiedad de los padres y susceptible de un tratamiento similar a otras propiedades privadas. Por ello, las conductas de desatención, maltrato, explotación y muerte de los pequeños ocurrían con mucha frecuencia. Es decir, que el niño se encontraba entre los siglos IV y XIII en una permanente situación de abandono. Por ello, bajo un supuesto cuidado y educación de los hijos, la forma más adecuada que encontraban los padres para esquivarlo era mediante el abandono dentro o fuera del hogar, la entrega a otras familias en adopción, como rehén o criado, o internándolo en un convento (De Mause, 1982). Por ello se comprende, debido a una gran extensión de la pobreza y del abandono, que el recurso asistencial por excelencia, bajo una concepción de tipo caritativo, fuera el hospital. En estas instituciones se recogía no sólo a los niños, sino a todo tipo de necesitados (Carmona, 1988). Previamente, continúa De Mause, hasta el siglo IV, la situación era aún más perniciosa, pues los padres solucionaban las ansiedades que les causaba el cuidado de los hijos recurriendo al infanticidio, justificando esta conducta en mitos religiosos o en sus precariedades. Todo ello, como se deduce de las explicaciones de Ariès (1987), con motivo de la ausencia de un sentimiento de infancia, de una consideración del niño como ser específico, independiente y particular. El niño permanecía mezclado con los adultos entre los que sobrevivía según sus propias experiencias de aprendizaje, no existiendo tampoco una institución educativa que estableciera los límites entre el colectivo infantil y el adulto a la hora de transmitirle los necesarios conocimientos. Ciertamente ese abandono padecido por los niños en la etapa medieval era una consecuencia de la falta de capacitación de los padres para establecer unas relaciones familiares de carácter empático con los niños y no tanto el reflejo de una determinada actitud social (Ocón, 1995). Por ello la adopción perseguía, generalmente como finalidades básicas, asegurar la continuación de la estirpe y la herencia o patrimonio de cargos públicos. Es 
decir, que como consecuencia de esta concepción social del niño, la adopción era un instrumento para satisfacer las necesidades de los adultos, y no una medida encaminada a solventar los intereses de los niños.

La familia, en este sentido, en el Imperio romano no sólo podía establecerse por lazos de sangre (naturae subjectae), sino a partir de otros lazos jurídicamente reconocidos (iure subjectae), quedando sus miembros bajo la autoridad del pater familia que, al ostentar poderes absolutos sobre todas las personas libres que conformaban la unidad familiar, podía vender o, incluso, matar a sus hijos (Rozemblum de Horowitz, 1990). El pater tenía, asimismo, la posibilidad de recurrir a la adopción para incorporar un miembro a su familia y, de esta forma, cubrir diversas necesidades: continuación del linaje familiar o la transmisión del patrimonio, asegurar el culto a los ancestros y elevar al adoptado, normalmente, a un nivel civil superior de patricio o ciudadano. Las personas adoptadas eran habitualmente de sexo masculino y, a menudo, adultas, en contraste con la moderna adopción de niños de uno y otro sexo (Chemin, 1974).

Desaparecido el Imperio Romano en Occidente por las invasiones bárbaras, su Derecho perduró en Oriente en el seno del Imperio Bizantino, recopilado y actualizado por la obra de Justiniano, quien, al suprimir los antiguos trámites, simplificó sobremanera los procedimientos (Padilla Piñol, 1988). En esta época (año 500 después de Cristo) existían dos clases de adopciones: la plena y la menos plena. La primera, que incorporaba totalmente al adoptado a su familia, tenía lugar cuando el adoptante era un ascendiente del adoptado. Por otra parte, cuando se confiaba el adoptado a una persona ajena a su círculo familiar conservando su situación familiar anterior y sin quedar sujeto a la patria potestas del adoptante, se producía la adopción menos plena. Normalmente, esta modalidad permitía al adoptado retener sus derechos hereditarios respecto a su familia de origen (Manaï, 1990).

Durante el largo periodo medieval, al ser considerada por el derecho feudal impropia la convivencia de señores y plebeyos, y haberse producido la desaparición de conservar la perpetuidad del culto doméstico, la institución de la adopción cayó en desuso (Rodrígues, 1997; Chavanneau de Gore, 1992). Esta circunstancia, junto a la ausencia del sentimiento de infancia, hacía que el aborto, el infanticidio y el abandono de niños fueran hechos muy frecuentes. Estos comportamientos serán prohibidos por la Iglesia a partir de los siglos XII y XIII (Ariès, 1987).

En los siglos que delimitan la Edad Moderna (XVI y XVII), también bajo una acuciante situación de pobreza, los recursos a disposición del menor seguirán siendo los hospitales complementados por una serie de instituciones de carácter asistencial-benéfico, como fueron los asilos u hospicios para niños, viejos, mujeres, desamparados, etc., persiguiendo objetivos económicos, filantrópicos, moralizantes y de carácter represor (Carmona, 1988). El recurso de la adopción continuará orientado por los objetivos del período anterior, si bien parece que 


\section{RIS}

no fue muy utilizado por la costumbre tan extendida de recluir a las personas en este tipo de centros. No obstante ya se perciben, frente a la Edad Media, cambios relevantes en las relaciones internas de la familia con el niño, pues esta institución asumirá una función moral y espiritual, aparte de la transmisión de la vida, de los apellidos y del patrimonio, así como un gran interés por su educación (Ariès, 1987). La familia y la escuela serán dos agentes fundamentales para la retirada del mundo de los adultos (Varela y Álvarez Uría, 1991).

El periodo ilustrado introducirá importantes cambios en todo lo relacionado con el niño. Según Ariès (1987) es durante el siglo XVIII cuando se produce la separación entre la familia y la sociedad que, incluso, puede observarse en una nueva reestructuración de la vivienda familiar. Es decir, que se percibe una necesidad de aislamiento imprescindible para el cultivo de una vida familiar privada entre padres e hijos, y con ella, el afloramiento de unas nuevas relaciones familiares. Este sentimiento de infancia, ya desarrollado, también afectará a la educación de los hijos, pues hará que las familias burguesas no admitan el contacto de sus hijos con las clases populares, recluyéndolos en internados y escuelas menores de los colegios. La Ilustración descubre a los niños como un grupo social, que son, por otra parte, los constructores de la futura sociedad, pero que todavía no albergan los derechos de los seres humanos adultos (López Méndez, 1999). Sin embargo, ya comienza a surgir una relación de empatía entre los adultos y el niño, caracterizada por la importancia de éste como objeto de protección (que supone una responsabilidad) más que una interacción basada en el afecto y estímulo que como persona-sujeto necesitaría (de Mause, 1982). Debido a la importancia del niño como un agente económico, el Estado hará ingresar a los niños en una serie de instituciones como las casas-cuna, casas de expósitos, Casas de Misericordia, etc., como forma de disminuir las altas tasas de mortalidad registradas en torno a esta época, que fueron también elevadísimas en los establecimientos ${ }^{2}$. Aunque los elementos fundamentales del sistema de "protección" a la infancia fueron las amas de cría, que alimentaban a los niños tanto en el interior como en el exterior de los centros. Respecto a la adopción, existían dos modalidades básicas: una "legalista" ante escribano público y testigos (ordinaria), y otra informal (la más común) por medio de la cual un ama "se queda con el niño hasta que lo pidan", aunque fue un recurso muy poco utilizado. Pero, dado que de la adopción no se derivaban consecuencias jurídicas, los niños eran frecuentemente devueltos a las instituciones del Estado (Álvarez Santaló, 1980: 104-105). En el terreno educativo los ilustrados manifestarán una gran preocupación pedagógica, como forma de aspirar a un amplio abanico de transformaciones sociales, pues sin educación no

\footnotetext{
${ }^{2}$ Para profundizar en estos aspectos: Redondo (1990), Gómez (1987), Santana (1993).
} 
sería posible la plasmación de un proyecto caracterizado por aspiraciones de tipo político y económico a partir de sujetos ilustrados, de ciudadanos cultivados (Ruiz Berrio, 1988; Moreno González, 1988). Aunque todavía no se puede hablar de la existencia de un sistema educativo elemental y generalizado, precisamente porque se pensaba que la educación era una actividad privada distribuida por estamentos bien diferenciados (Guerrero, 1996).

Ya en el siglo XIX se observa un cierto afán por conducir a los niños por el buen camino, y este celo explica la necesidad de la aparición del Estado Protector (de Mause, 1982). Bajo estos presupuestos, la familia se convierte en una institución socializadora básica para la interiorización del niño de los contenidos propios de la cultura circundante, que posibilita la configuración definitiva del sentimiento de infancia (Ariès, 1987). El padre ejercerá un papel más instrumental, racional y conectado con el mundo exterior, y la madre desempeñará un liderazgo expresivo, afectivo e integrador orientado al núcleo familiar, convirtiendo al hijo en un súbdito (Borderies-Guereña, 1996). Desde ahora el Estado intervendrá de forma más intensa sobre el colectivo infantil para protegerlo de la marginación, por medio de diferentes medidas protectoras. Se produce la plena implicación de los padres en el desarrollo de la vida del niño, esforzándose por empatizar con él y satisfacerle en sus particulares y progresivas necesidades, por ser considerado ya como un sujeto con derechos personales y como una entidad dependiente de los deseos de sus padres y de las decisiones de los adultos (de Mause, 1982). No obstante, sigue aún manteniéndose una imagen de la infancia como un colectivo dependiente con rasgos todavía propios de la etapa benéfico-asistencial reflejada en la legislación de la época.

El despegue definitivo de la infancia como un grupo con características y necesidades propias, susceptible de una protección especial, se producirá en España en torno a los años ochenta, a partir de la Constitución Española de 1978 y de la ley 1/1987, de 11 de noviembre, que modificará el Código Civil y la Ley de Enjuiciamiento Civil en materia de adopción; así como en la actual Ley 1/ 1996, de 15 de enero, de Protección Jurídica del Menor, que supone la culminación histórica de la protección de este colectivo, en línea con los principios de la normativa internacional, y de modo especial, con la Declaración de los Derechos del Niño de 1989. La protección de la infancia ya será una responsabilidad del Sistema Público de Servicios Sociales, desvinculándose de las reminiscencias anteriores, y la protección y el mismo proceso adoptivo serán controlados desde su mismo inicio por la Administración. El niño pasa a ser un sujeto activo de Derecho con capacidad para ir disfrutando de un elenco de derechos y libertades de forma progresiva, según un principio que se perfila como el más elemental de todos: la primacía superior de su interés sobre cualquier otro que pudiera concurrir. Un análisis de los contenidos que configuran las Leyes mencionadas nos ayudará a comprender la importancia de estos cambios. 


\section{EVOLUCIÓN DE LA ADOPCIÓN EN LA LEGISLACIÓN ESPAÑOLA}

El tema de la adopción quedó reflejado en algunas legislaciones europeas como la española (Fuero Real, Partidas, recopilaciones y códigos), aunque no en las costumbres, según algunos autores (Amorós 1987: 22) 3 $^{3}$ En dichas normativas jurídicas españolas se regularon el prohijamiento y la crianza. El prohijamiento permitía a cualquier hombre sin descendientes legítimos recibir por hijo a cualquier varón o mujer capaz de heredarle, pudiendo prohijar los hombres libres que les separasen dieciocho años respecto al prohijado y que no fuesen impotentes. Por su parte, la crianza consistía en una típica institución asistencial que conllevaba el confiamiento de un menor a una familia para que lo cuidara (alimentara) y enseñara durante un período de tiempo determinado, sin que esta circunstancia diera lugar al establecimiento de vínculos familiares ni a la ostentación de derechos hereditarios (Rozemblum de Horowitz, 1990; Chavanneau de Gore, 1992).

Si bien la institución de la adopción permanece, parece ser que su utilización práctica ha sido muy escasa, respondiendo en la sociedad española, incluso hasta la Ley $21 / 87$ de 11 de noviembre ${ }^{4}$, a los intereses de los adoptantes más que a la satisfacción de las necesidades y derechos de los adoptados. Posteriormente surgirá la actual Ley Orgánica 1/1996 de Protección Jurídica del Menor ${ }^{5}$, cuyos contenidos regulan el actual marco de protección.

Los precedentes más recientes de la Ley 21/1987 pueden encontrarse en el Código Civil de 1889, el cual, aunque inspirado en el francés de Napoleón, que distinguía entre la adopción ordinaria o remuneratoria y testamentaria; sin embargo, el español sólo recogía una tipología de adopción. Tenían capacidad para adoptar aquellas personas que, hallándose en pleno uso de sus derechos civiles, hubieran cumplido cuarenta y cinco años y tuvieran quince años más que el adoptado. Estas normas protegían más los derechos del adoptante y de su familia natural que los del adoptado, gozando éste de menos derechos que los hijos naturales del adoptante (Padilla Piñol, 1988).

Como consecuencia del escaso resultado que dieron las normas respecto a la adopción contenidas en el Código Civil, básicamente por dificultades de tramitación, surge una modalidad de adopción, por Ley de 17 de octubre de 1941,

\footnotetext{
${ }^{3}$ En referencia al proyecto de elaboración del Código Civil de 1851, señala: "Es un hecho constante y notorio que la Adopción no está en nuestras costumbres. Hubo por lo tanto, en la Sección una casi unanimidad para pasarla en silencio; pero habiendo presentado un vocal andaluz, que en su país había algunos casos, aunque raros, de ella, se consintió en dejar este título, con la seguridad de que sería tan rara y extraña en adelante como lo había sido hasta ahora" (1987, pp. 22).

${ }^{4}$ B.O.E. Núm. 275 , de 17 de novicmbre.

${ }^{5}$ B.O.E. Núm. 15, de $17 \mathrm{de}$ cnero.
} 
orientada a los acogidos en las Casas de Expósitos y en otros establecimientos de benefícencia. Esta Ley permitía a los administradores de estos centros la exclusividad en la tramitación de los expedientes de adopción, los cuales, posteriormente, habría de aprobar el Juez, así como el seguimiento del menor y la vigilancia de la conducta del adoptante. Sin embargo, el hecho de que los padres naturales pudieran impugnar la adopción y recuperar al hijo, tras ser escuchado si era mayor de 14 años, impidió a muchas personas optar por este recurso. A consecuencia de la Guerra Civil española se produjo un gran aumento de niños huérfanos y abandonados, creándose una institución afín a la adopción denominada prohijamiento o colocación familiar, con carácter permanente o temporal (regulada por Orden de 1 de abril de 1937). Era gestionada por las Juntas de Protección de Menores $\mathrm{y}$, frecuentemente, derivaba en adopción (Céspedes Mac-Crohon, 1950: 22-23).

Con posterioridad, el Código Civil fue reformado por Ley de 24 de abril de 1958, introduciendo un obstáculo para el proceso de adopción, al situar en tres años el tiempo que un niño había de permanecer abandonado para poder ser adoptado, criterio que, sin duda, supuso un impedimento para la salida de muchos niños de los centros de internamiento. Distinguió, como en el Derecho Romano, dos modalidades de adopción: la plena y la menos plena. La primera, destinada a hijos de padres desconocidos, abandonados o expósitos de menos de 14 años que tuvieran una diferencia de edad, al menos, de dieciocho años con el adoptante, y que éste fuera mayor de treinta y cinco años. Por otra parte, la menos plena, mantenía las características reflejadas en el Código precedente y el adoptado podía conservar los apellidos de sus padres naturales (Amorós, 1987: 90-91; Padilla Piñol, 1988: 15).

A continuación, la Ley 7 de julio de 1970 mantiene las dos tipologías de adopción, la menos plena y simple, posibilitando la transformación de esta última en aquélla. La aprobación de la Constitución Española de 1978 introduce sustanciales modificaciones en el tema de la filiación (art. 14, 32 y 39), sancionando la plena igualdad entre los hijos con independencia de su filiación. Una de las consecuencias de la introducción de estos principios constitucionales fueron las leyes de 13 de mayo y 7 de julio de 1981, las cuales, al cancelar definitivamente la distinción entre la filiación legítima e ilegítima, posibilitan su establecimiento por naturaleza o adopción (art. igualdad entre padre y madre, y la posibilidad de investigación para el establecimiento de la paternidad (art. 108 del Código Civil). Las reformas del Código operadas por estas leyes produjeron, entre otras, las siguientes innovaciones: los hijos adoptivos quedaron equiparados en derechos y obligaciones a los hijos biológicos; rebaja la edad del adoptante a treinta años y la diferencia con el adoptado a dieciséis; posibilita la adopción a personas con descendencia; se reduce el tiempo que el niño ha de estar en situación de abandono a treinta días (antes estaba en seis meses); se reserva la adopción plena para menores de catorce años y la menos plena para los restantes; establece diferentes grados de consentimiento, etc. 
R I S

REVISTA INTERNACIONAL DE SOCIOLOGIA

No 33, Septiembre-Diciembre, 200'2

PEDRO CASTIÓN BOYER Y JOSÉ OCÓN DOMINCO

Las características jurídico-sociales distintivas que va a mostrar la adopción en la actualidad, tras el impulso que supusieron los acontecimientos de la Segunda Guerra Mundial para esta institución, van a quedar reflejadas, en lo que respecta al Estado Español y de acuerdo con la legislación internacional ${ }^{6}$, en las ya mencionadas Leyes 21/1987 de 11 de noviembre y 1/1996 de 15 de enero. Estas Normas van a producir, por otra parte, las correspondientes modificaciones del Código Civil y de la Ley de Enjuiciamiento Civil.

En efecto, si bien el marco actual estatal de protección de la infancia, sin perder de vista el referente máximo que supone la Constitución Española de 1978, está representado por la Ley Orgánica 1/1996, sin embargo, la Ley 21/1987, frente a concepciones anteriores muy centradas en la satisfacción de los adoptantes, ha supuesto, además de introducir el acogimiento familiar y suprimir la figura de la adopción simple, importantes cambios y modificaciones en lo relativo a la defensa del interés superior del menor. A raíz de la misma, el anticuado concepto de abandono fue sustituido por el actual de desamparo ${ }^{7}$, cambio que, por otra parte, ha agilizado sobremanera los procedimientos de protección. Esta Norma concibe la adopción como una medida de integración familiar fundamentada en el beneficio del adoptado sobre cualquier otro que pudiera concurrir, y atribuye a las entidades públicas la competencia para decidir sobre la constitución del acogimiento familiar y presentar ante el juez las propuestas con las que se debe iniciar el expediente de adopción. No hemos de olvidar que antes de la Ley de 1987, la adopción se constituía por medio de un acto privado jurídico ante el Juez. Asimismo, se procede a una nueva regulación de los requisitos y prohibiciones para adoptar (art. 175 del Código Civil) y se reordena el apartado correspondiente a los consentimientos necesarios para la constitución de la adopción (art. 177 del Código Civil).

La posterior promulgación de la Ley 1/1996 (como se recoge en la Exposición de Motivos) ha desarrollado aún más este marco de protección, introduciendo algunas innovaciones en conformidad con el surgimiento de nuevas necesidades y demandas sociales, y por la necesidad de paliar determinadas lagunas que la

\footnotetext{
${ }^{6}$ En esta línea, nuestra la Constitución Española de 1978 señala en su artículo 39.4: "Los niños gozarán de la protección prevista en los acuerdos internacionales que velan por sus derechos". Con relación a ellos, nos referimos, básicamente, en función de este trabajo, a la Convención de las Naciones Unidas sobre los Derechos del Niño, de 20 de noviembre de 1989 (ratificado por España el 30 de noviembre de 1990 -B.O.E. Núm. 313, de 31 de diciembre) y al Convenio relativo a la protección del niño y a la cooperación en materia de adopción internacional: La Haya, 1993 (en vigor para España desde 1 de noviembre de 1995; B.O.E. de 1 de agosto).

7 "Se considera situación de desamparo la que se produce de hecho a causa del incumplimiento o inadecuado cjercicio de los deberes de protección establecidos por las leyes para la guarda de menores, cuando éstos queden privados de la necesaria asistencia moral o material" (Art. 172.1 del Código Civil).
} 
aplicación de la Ley 21/1987 había puesto de manifiesto durante su vigencia. En virtud de la esta Ley, el artículo 176.1 del Código Civil establece que la adopción se constituye por resolución judicial, teniendo en cuenta siempre el interés del menor, y que la persona o personas adoptantes sean idóneas para ejercer la patria potestad. Asimismo, requiere que el adoptante sea mayor de veinticinco años, o bien, en el supuesto de que adopten ambos miembros de la pareja, al menos uno de ellos ha de tener esta edad. En todo caso, debe de existir una diferencia de al menos catorce años entre uno de los adoptantes y el adoptado (art. 175.1). De igual modo, para llevar a cabo la adopción, es necesaria la propuesta de la entidad pública, excepto cuando el adoptando es huérfano y pariente del adoptante en tercer grado por consanguinidad o afinidad; que sea hijo del consorte del adoptante; que lleve un año bajo la figura de acogimiento preadoptivo o tutela ${ }^{8}$; y que sea mayor de edad o menor emancipado (art. 172.6 del Código Civil).

En torno a los requisitos, el artículo 177.1, señala: "Habrán de consentir la adopción, en presencia del Juez, el adoptante o adoptantes y el adoptado mayor de 12 años". Este artículo, en su apartados 2 y 3 , se refiere a los asentimientos y a quienes han de ser oídos, si bien, por motivos de espacio, no serán recogidos. Tras la cumplimentación de cada uno de los requisitos, el Juez se encuentra en disposición de constituir la adopción, cuyos trámites se encuentran regulados en los artículos 1.829 y siguientes de la Ley de Enjuiciamiento Civil. Así, pues, aunque pudiera haber expedientes de adopción incoados bajo la Ley 21/1987, en los que no haya recaído resolución judicial, sin embargo, "no hay diferencias sustanciales entre el expediente de la ley de 1987 y el de la ley de 1996" (Serrano,1997: 54).

Finalmente observamos que la Ley también regula, aunque de modo quizás insuficiente, la adopción internacional con la intención de adaptarla a los Convenios ratificados por España: Convención de los Derechos del Niño, de Naciones Unidas, de 20 de noviembre de 1989 (ratificado por España el 30 de noviembre de 1990) y Convenio relativo a la protección del niño en materia de adopción internacional, hecho en La Haya el 29 de mayo de 1993 (ratificado por España el 27 de marzo de 1995). Para ello, la Ley 1/1996 modifica los apartados 4 y 5 del artículo 9 del Código Civil sobre Derecho Internacional Privado. En todo caso, se regula en su artículo 9.4: "El carácter y el contenido de la filiación, incluida la adoptiva y las relaciones paterno-filiales, se regirán por la Ley personal del hijo y si no pudiera determinarse ésta, se estará a la de la residencia habitual del hijo" (por Disposición final primera de la Ley 1/1996). Asimismo, en su artículo 9.5, párrafo $5^{\circ}$, se introduce: "No será reconocida en España como adopción la

\footnotetext{
8 "Cada entidad pública designará el órgano que ejercerá la tutela de acuerdo con sus estructuras orgánicas de funcionamiento" (art. 18.2 de la Ley Orgánica 1/1996). El número de altas de tutelas ex lege en España, a excepción de la Diputación Foral de Vizcaya, respecto al último año del que disponemos de datos (1997) fue de 3.635 (Subdirección General de Programas de Servicios Sociales, 1999).
} 
constituida en el extranjero por adoptante español, si los efectos de aquélla no se corresponden con los previstos por la legislación española. Tampoco lo será, mientras la entidad pública competente no haya declarado la idoneidad del adoptante, si éste fuera español y estuviera domiciliado en España al tiempo de la adopción" (por Disposición final segunda de la Ley 1/1996). De esta forma, con el fin de evitar las adopciones sin control estatal, introduce un certificado de idoneidad como requisito indispensable para adoptar internacionalmente. Para solucionar las situaciones de falta de correspondencia entre las legislaciones con otros países, el Ministerio de Justicia, a través de la Dirección General de los Registros y del Notariado, ha arbitrado una serie de procedimientos que posibilitan, a posteriori, la transformación de una adopción simple en plena o la obtención del certificado de idoneidad (siguiendo lo estipulado en el artículo 27 del convenio de La Haya de 1993) .

Evidentemente, el cambio legislativo se ha ido produciendo a medida que la mentalidad de la sociedad sobre los menores ha ido cambiando. Sobre el tema de la adopción, en líneas generales, y como hemos apuntado más arriba, la transformación básica que se ha dado es que en el pasado la adopción pertenecía al ámbito de lo privado, se realizaba entre personas privadas, mientras que ahora pertenece al ámbito de lo público. Es decir, el control pasa a la administración durante todo el proceso de adopción. Esta intervención ha traído consigo importantes cambios, tanto desde el punto de vista de la selección de los padres más adecuados para una adopción, como desde la perspectiva del niño: no se trata de adoptar a cualquier niño sino a uno con unas características muy determinadas. Gracias a los avances en el conocimiento de las necesidades y desarrollo de los niños, las relaciones en el seno familiar también se han modificado. En definitiva, a lo largo de los siglos, la adopción ha proporcionado a los niños una familia, pero, frente a etapas anteriores, actualmente priman los intereses del menor sobre cualesquiera otros que pudieran concurrir. No hemos de olvidar que nadie tiene derecho a la adopción a excepción del niño.

Estas características modernas de la adopción conviene situarlas en un contexto de transformaciones más generales que se están produciendo en el papel de la infancia en la sociedad y en las funciones y estructuras familiares. Respecto a lo primero, en el papel de los menores, de los hijos en la sociedad, se ha pasado de

\footnotetext{
${ }^{9}$ Otra situación de falta de correspondencia se produce cuando la legislación del país de origen permite a los padres la facultad de extinguir la adopción por propia voluntad y esta circunstancia constituye la única diferencia con la legislación española. Para solventar estas situaciones se añade un párrafo final al apartado 5, del artículo 9 del Código Civil, por Ley 18/1999, de 18 de mayo, que indica: "La atribución por ley extranjera de un derecho de revocación de la adopción no impedirá el reconocimiento de ésta si se renuncia a tal derecho en documento público o por comparecencia ante el encargado del Registro Civil" (Artículo único) (B.O.E. Núm. 119, de 19 de mayo).
} 
RIS

REVISTA INTERNACIONAL DE SOCIOLOGIA

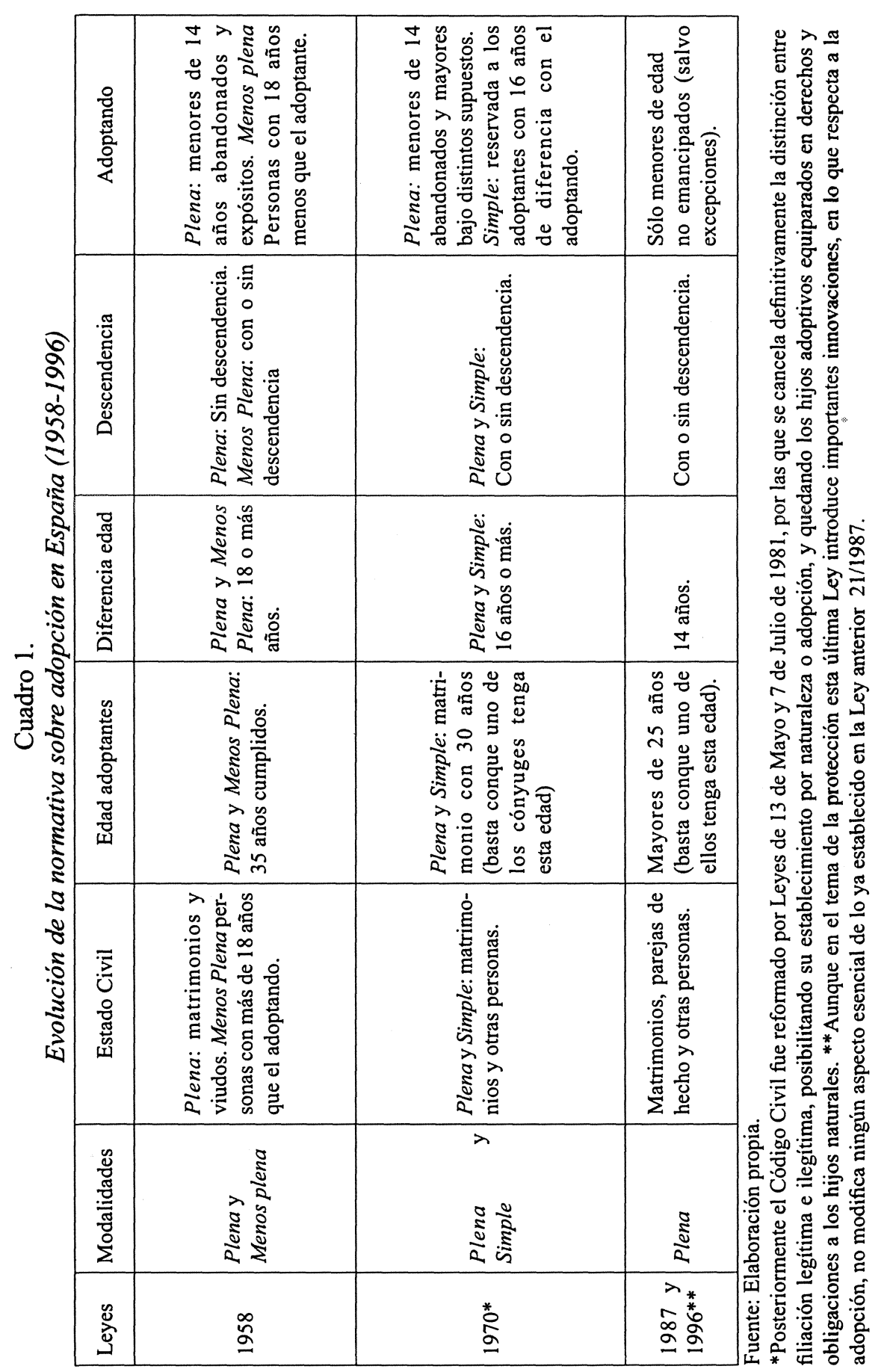


R I S

REVISTA INTERNACIONAL DE SOCIOLOCIA

№ 33, Septiembre-Diciembre, 2002

PEDRO CASTÓN BOYER y JOSÉ OCÓN DOMINCO

considerar exclusivamente a los adultos como sujeto de derechos, a la consideración prioritaria de los derechos de los niños. En este sentido, en el Preámbulo de la Convención de los derechos del Niño de Naciones Unidas de 1989, se proclama que "el niño por su falta de madurez física y mental, necesita de protección y cuidado especiales, incluso la debida protección legal, tanto antes como después del nacimiento"10. Y respecto a los cambios en la estructura y funciones de la familia, la demanda de adopciones se explica mejor cuando la ponemos en relación con determinadas transformaciones que se están produciendo en la familia, tales como la disminución del número de hijos, el aumento de la edad a la maternidad, de solteros y solteras por libre opción, de los hogares monoparentales, la cohabitación de gays y lesbianas, etc. (Iglesias de Ussel, 1983 y 1984).

\section{SOCIOLOGÍA DE LA ADOPCIÓN EN ESPAÑA}

Una vez situado el problema de la adopción histórica y jurídicamente, a continuación presentamos algunos datos de las investigaciones realizadas en España hasta la fecha sobre este tema. En nuestro país son muy escasos los estudios en torno a la práctica de la adopción y sobre las cuestiones relacionadas con ella, como la comparación de los niños adoptados con los que gozan de una familia normal o se encuentran atendidos bajo otros recursos.

Las principales y únicas investigaciones publicadas en España sobre la adopción, desde una perspectiva psicosociológica y educativa, corresponden, por orden cronológico, a los siguientes autores: Pedro Amorós que publicó una investigación en 1987 referida a Cataluña, Martí X. March en 1993 en Mallorca, y Jesús Palacios, Yolanda Sánchez y Encarna Sánchez en Andalucía en 1997. En adelante nos referiremos a estos estudios con los nombres del ámbito geográfico donde han sido realizadas.

La investigación de Cataluña (1987)" pretende, entre otros objetivos, describir y comparar cómo se ha desarrollado el proceso de adopción en dos grupos de

\footnotetext{
${ }^{10}$ En el resto del articulado "no se hace referencia a la atención prenatal. La legalización del aborto en muchos de los países lleva a la Comisión a no entrar en tan polémico tema, lo que marca una clara diferencia con lo establecido en la Declaración de 1959. No obstante, este problema queda de alguna forma subsanado por el compromiso que asumen los Estados partes (en el artículo 24.2.d), que asegura la atención sanitaria prenatal y postnatal apropiada a las madres" (Álvarez Vélez, 1994: 101).

"Los datos relativos a esta investigación han sido consultados directamente en la tesis doctoral de P. Amorós (1986): La adopción desde una perspectiva socioeducativa (Aspectos psicosociales y educativos). Barcelona. Departamento de Pedagogía experimental, Terapéutica y Orientación. Facultad de Filosofia y Ciencias de la Educación. También su obra, referida a su tesis doctoral (1987): La adopción y el acogimiento familiar. Una perspectiva socioeducativa. Madrid, Narcea.
} 
familias: un grupo que adoptó directamente a través de la Diputación de Barcelona y otro formado por familias que adoptaron tras un período en régimen de acogimiento familiar. Igualmente relaciona de forma significativa los diferentes factores que conforman este proceso. La muestra estuvo compuesta por 114 adoptados (55 directamente y 59 tras un tiempo en acogimiento) insertos en un total de 108 familias. Los niños/as seleccionados habían nacido entre 1972 y 1975 (ambos inclusive), razón por la cual cuando fueron estudiados tenían entre 9 y 12 años. El procedimiento utilizado para la recogida de datos fue la entrevista de carácter estructurada y, para el tratamiento de los datos, el autor utilizó la metodología del análisis de contenido.

El trabajo realizado en la ciudad de Mallorca por Martí X. March Cerdá (1993) ${ }^{12}$ describe y compara cómo se ha desarrollado el proceso de adopción llevado a cabo por dos grupos de familia entre los años 1981-1987, tras cinco años de vigencia de la Ley de Adopción 21/1987. La muestra estuvo compuesta por 37 niños y 43 niñas que había sido adoptados entre los años 1981 y 1987 por 80 familias. La edad de los adoptados en el momento del estudio se distribuía entre los 4 y 21 años, aunque el $75 \%$ pertenecía al intervalo 4-12 años. La metodología utilizada es muy similar a la utilizada en la investigación realizada en Cataluña.

Y la tercera investigación existente es la de Jesús Palacios, Yolanda y Encarna Sánchez, (1997) ${ }^{13}$ en la Comunidad Autónoma de Andalucía por encargo de la Junta. Y trata de verificar temas como si la adopción es un recurso adecuado para los menores, la dinámica concreta que produce la incorporación del niño a la familia, los papeles que desempeñan los equipos técnicos, las necesidades que tienen los padres, etc., bajo la regulación estatal proporcionada por la Ley 21/1987. La muestra recoge a 393 familias que adoptaron niños/as en el período comprendido entre los años 1988-1993, ascendiendo a un total de 484 sujetos. En este trabajo los autores proceden al estudio y comparación de los niños adoptados (210) con tres grupos diferentes de niños: sus compañeros actuales (314), aquellos que hubiesen sido sus compañeros de no haber sido adoptados (219) y, por último, los niños que habiendo salido de su entorno originario estuvieron bajo algún tipo de cuidado residencial o institucional (122). Respecto a los instrumentos de medida, entrevistaron a cada una de las familias adoptivas con relación a los temas de mayor interés, y recogieron los resultados de una serie de cuestionarios y escalas en torno al apoyo social recibido y recursos disponibles, a los estilos educativos y a las relaciones entre padres e hijos, a los problemas de conducta

${ }^{12}$ La adopción en Mallorca. Una investigación evaluativa. Palma de Mallorca, Universidad de las Islas Baleares y Consejería de Gobernación y Dirección General de la Juventud, Menor y Familia.

${ }^{13}$ La adopción en Andalucia (1997). Sevilla, Junta de Andalucía, Consejería de Asuntos Sociales (Dirección General de Atención al Niño). 
observados, etc. ${ }^{14}$. Para estudiar los otros tres grupos de niños, que hizo posible la comparación con el grupo de los adoptados, utilizaron varios procedimientos ${ }^{15}$.

Con el fin de proporcionar una información detallada sobre este comportamiento alternativo a la familia biológica, vamos a exponer y comparar los resultados más pertinentes cosechados por los tres autores. Las investigaciones de Pedro Amorós y Martí March distinguen, haciendo referencia a adoptantes y adoptados, un grupo de adopción (familias que adoptaron directamente del centro de acogida a los niños) y un grupo de guarda (familias que adoptaron tras un período previo de acogida familiar). Presentaremos los datos de ambos estudios de forma conjunta, sin distinguir grupos, salvo en el estudio sobre Cataluña que, en ocasiones, no se encuentran elaborados globalmente.

\section{PERFIL DE LAS FAMILIAS ADOPTANTES}

Analizaremos en este apartado las variables más relevantes de los tres estudios respecto a las familias adoptivas: edad, profesión, nivel educativo, composición de las familias, etc. En general se puede afirmar que el perfil de las familias adoptivas es bastante plural, pues de los datos que aportan las tres investigaciones no se deduce una mayor influencia de una variable sobre otras en la decisión de las parejas para adoptar.

Edad, categoría profesional, nivel educativo y composición de las familias adoptantes

Respecto a la variable edad, generalmente los padres adoptantes suelen tener más edad que los padres naturales. Posiblemente porque deciden adoptar una vez que han comprobado que no pueden tener hijos, y este hecho retrasa la adopción. En las investigaciones de Cataluña y Baleares, los porcentajes más altos de parejas

\footnotetext{
${ }^{14}$ Entrevista sobre el Proceso de Adopción (EPA), Escala de Apoyo Social (EAS), Escala de Evaluación de Estilos Educativos (4E) y el Informe de los Padres sobre la Conducta de los Niños (IPCN).

${ }^{15}$ Mientras que en el caso de los adoptados los investigadores pudieron contar con los padres y los profesores para estudiar diferentes aspectos, para los otros tres grupos de niños sólo contaron con la información de los profesores. Así, para evaluar la conducta de los niños en el aula, utilizaron distintas versiones del Classroom Behavior Inventory (CBI) con sus diferentes escalas y el cuestionario de problemas de conducta en su versión preescolar (Q5) o escolar (Q6) y, para evaluar a los mayores de 12 años, se sirvieron de un cuestionario de malestares. También a los niños se les aplicó individualmente la versión correspondiente a su edad de la escala de autoestima (Perceived competence scale for children).
} 
adoptantes se encuentran entre los padres y madres que tienen entre 30 y 39 años. En Cataluña hay más madres que padres comprendidos en esas edades y en Mallorca algo más de padres (tabla 1). Y en Andalucía más de la mitad de la muestra se ubica en el rango comprendido entre los 36 y 45 años (Palacios y otros, 1997: 38-39). En los tres estudios le sigue en importancia los padres comprendidos entre 40 y 49 . Son muy pocas las parejas que adoptan antes de los 30 años y muchas menos las que lo hacen después de los cincuenta.

Otra variable de interés es la categoria profesional (tabla 2). En general, en contra de lo que se pueda pensar, son las familias de profesiones cualificadas y no las compuestas por cuadros superiores las que más adoptan. En Cataluña y Mallorca son los trabajadores y trabajadoras de la industria los que realizan un mayor número de adopciones: un $39,5 \%$ de padres lo hacen en Cataluña y un $43,7 \%$ en Mallorca. Estos porcentajes de adopciones, sin embargo, son de un $23,7 \%$ entre los cuadros superiores de Cataluña y de un 17,5\% en Mallorca. En el

Tabla 1.

Edad de las familias en el momento de la acogida/adopción en Cataluña y Mallorca (porcentajes verticales)

\begin{tabular}{lccccc}
\hline \multirow{2}{*}{ Años } & \multicolumn{2}{c}{ CATALUÑA } & & \multicolumn{2}{c}{ MALLORCA } \\
\cline { 2 - 3 } \cline { 5 - 6 } & Padres & Madres & & Padres & Madres \\
\hline Menos de 30 & 5,3 & 8,8 & & 3,7 & 20,0 \\
De 30 a 39 & 50,0 & 63,2 & & 55,0 & 52,5 \\
De 40 a 49 & 44,7 & 28,1 & & 32,5 & 21,2 \\
Más de 50 & 0,0 & 0,0 & & 6,2 & 5,0 \\
NS/NC & 0,0 & 0,0 & & 2,5 & 1,2 \\
Totales & 100,0 & 100,0 & & 100,0 & 100,0 \\
\hline
\end{tabular}

Fuente: Amorós (1986, 1987); March (1993). Elaboración propia.

estudio de Andalucía los padres adoptantes cualificados giran alrededor del $43 \%$ y las madres el $37 \%$; mientras que entre los técnicos superiores estos porcentajes sólo son de un 14 y un 13\% respectivamente (Palacios et al., 1997: 39).

El nivel educativo de la mayoría de estas familias está en consonancia con la categoría profesional de las familias adoptantes. En Mallorca, un 57, 5\% de los padres y un $55 \%$ de las madres sólo poseen estudios primarios y, únicamente, un $11,2 \%$ de los padres y un $8,7 \%$ de las madres estudios superiores. En Andalucía, la mitad de la muestra estudiada sólo tiene estudios básicos o menos, y el $50 \%$ restante se divide casi por igual entre los que tienen estudios secundarios y superiores (Palacios et al., 1997: 39). 
RIS

REVISTA INTERNACIONAL UE SOCIOLOGIA

Tabla 2.

Categoria profesional de los padres en el momento de acogida (porcentajes verticales)

\begin{tabular}{lcrr}
\hline \multirow{2}{*}{ Nivel Profesional } & CATALUÑA & \multicolumn{2}{c}{ MALLORCA } \\
\cline { 2 - 4 } & "Padres" & Padre & Madre \\
\hline Cuadros superiores & 23,7 & 17,5 & 7,5 \\
Cuadros medios & 20,2 & 12,5 & 5 \\
Comerciantes y autónomos & 16,6 & 25,0 & 11,2 \\
Trabajadores de la industria & 39,5 & 43,7 & 41,2 \\
Amas de casa & - & - & 33,7 \\
NS/NC & - & 1,2 & 1,2 \\
TOTALES & 100,0 & 100,0 & 100,0 \\
\hline
\end{tabular}

Fuente: Amorós (1986); March (1993). Elaboración propia.

El modelo de familia más representativo entre los adoptantes es el de relación de pareja. Por razones derivadas de la muerte del cónyuge o del divorcio tras la adopción, en Mallorca se dan algunos casos aislados de modelo monoparental: un $2,5 \%$ de una mujer con hijo, y un $1,2 \%$ también de padre con hijo adoptado. En Andalucía, a excepción de un 4\% de familias monoparentales, en el $96 \%$ de los casos son parejas las que adoptan, si bien un $15 \%$ de éstas son familias compuestas por dos núcleos.

Finalmente, en cuanto al número de hijos ${ }^{16}$, la gran mayoría de las familias tan sólo tienen el hijo adoptado (Tabla 3). Es decir, son mayoritarias las familias que adoptan porque no pueden tener hijos biológicos. En Cataluña las familias con un hijo adoptado son el 49\% de la muestra y en Mallorca el 62,5\%. En Andalucía ocurre igual, el $66 \%$ de las familias tienen sólo el hijo adoptado, el $24 \%$ dos y el resto más de tres hijos. De las familias con más de un hijo, además de los adoptados el 14\% tiene también hijos biológicos. Considerando sólo a las familias con los hijos adoptados, el $78 \%$ de las familias andaluzas han adoptado un niño, un $20 \%$ dos, y unos pocos han adoptado a tres o más niños (Palacios et al., 1997: 38).

${ }^{16}$ Ninguna de las tres investigaciones recoge el número de hijos biológicos que la pareja tenía antes de adoptar, en el caso de tener más de un hijo. 
Tabla 3.

Número de hijos en el seno familiar (porcentajes verticales)

\begin{tabular}{lcc}
\hline Número de hijos & CATALUÑA & MALLORCA \\
\hline Un adoptado & 49 & 62,5 \\
Dos adoptados & 30 & 21,2 \\
Adoptados y biológicos & 21 & 15,0 \\
NS/NC & - & 1,2 \\
TOTALES & 100,0 & 100,0 \\
\hline
\end{tabular}

\section{Motivación para adoptar}

El principal motivo por el que las familias adoptan es el deseo de tener o ampliar el número de hijos. Parecen poseer la mentalidad de que no hay familia si no se tienen hijos. En Cataluña el $67 \%$ de los padres del grupo de Adopción y el $71 \%$ del grupo de Guarda señalan que les movió a adoptar el deseo de fundar una familia, y son muy pocos los que adoptaron porque querían aumentar la familia (18 y $15 \%$ respectivamente). En Mallorca, con casi idénticos porcentajes, figuran los motivos de constituir una familia (32,5\%) y el buscar compañía (33,7\%). También en Andalucía, el $60 \%$ de las familias decidieron adoptar porque no podían ser padres biológicos y muy pocos aducen motivos altruistas para la adopción $(11 \%)^{17}$.

\section{Capacidad para la acogida}

La mayoría de las familias que adoptan prefieren niños normales física y psicológicamente, y son bastantes pocas las familias que solicitan o no les importan niños con características especiales. Estas últimas son las que tienen una motivación más altruista, adoptando niños con algún tipo de problemas.

En Andalucía el $62 \%$ de las adopciones lo fueron de niños normales y el $38 \%$ de niños especiales ${ }^{18}$. Considerando sólo estas últimas adopciones, el $62 \%$ de las familias eligieron de antemano niños con algunas características especiales y el

\footnotetext{
${ }^{17}$ En las investigaciones de Cataluña y Mallorca no se destaca este motivo específicamente.

${ }^{18}$ Los estudios de Cataluña y Mallorca no recogen el número de adopciones normales y especiales realizadas. No obstante, el apartado sobre Perfil de los adoptados, que trataremos más adelante, nos proporciona alguna idea sobre el tema.
} 
RIS

REVISTA INTERNACIONAL DE SOCIOLOCI

N 33, Septiembre-Diciembre, 2002

PEURO CASTÓN BOYER Y JOSÉ OCÓN DOMINGO

$22 \%$ los solicitaron así una vez conocidos. El resto (16\%) aceptó la adopción especial para agilizar los trámites o por la imposibilidad de formalizar una adopción normal. Los rasgos de adopciones especiales que se dieron en Andalucía fueron: un $41,8 \%$ fueron niños con minusvalías o deficiencias, un $39,8 \%$ con seis o más años, un $29 \%$ fueron adoptados hermanos y un $8,7 \%$ de otra etnia ${ }^{19}$. Para los autores "las adopciones especiales no son residuales ni accidentales, ni forzadas, sino consecuencias de una intención específica" (Palacios et al., 1997: 144).

A las familias que ya habían adoptado se les hizo la pregunta sobre la adopción especial, si decidiesen adoptar. Evidentemente la mayoría prefiere niños sanos. En Andalucía, el $65,9 \%$ de las familias manifestaron preferencias por niños sanos, un $17,2 \%$ se mostró abierto a considerar otros problemas y un $15,1 \%$ los adoptarían con enfermedades, siempre en función de su cronicidad y estado. Una gran parte de estas familias andaluzas $(41,5 \%)$ respondieron preferirlos de piel blanca. El mayor rechazo recae sobre los niños norteafricanos $(29,5 \%)$ y el menor sobre los europeos (8\%). En Cataluña y Mallorca, las familias no adoptarían, en primer lugar, a niños con problemas psíquicos (el 58,7\% de padres en Mallorca y el 47\% de padres de ambos grupos en Cataluña); después a niños mayores de siete años (en Cataluña el 50,9\% del grupo de Adopción y el 31\% del grupo de Guarda; y en Mallorca el 43,7\%), los niños con problemas físicos y sensoriales y los grupos de hermanos.

\section{La iniciativa de la adopción y las consultas familiares}

En Cataluña y Mallorca la iniciativa para adoptar surge normalmente de la pareja, si bien en Cataluña deciden conjuntamente más familias (64\%) que en Mallorca $(55 \%)$. En Andalucía la pareja lo decide sólo en un $19 \%$ de casos, surgiendo de la madre la iniciativa de adoptar en la mayoría de las ocasiones (60\%) (Tabla 4).

Con relación a las consultas familiares, en Cataluña un 54\% de las parejas del grupo de Adopción y un 39\% del grupo de Guarda toma la decisión la pareja sola y la mantienen en secreto; frente al $40 \%$ y al $39 \%$ de ambos grupos que dicen haberlo comunicado a sus familias. En Mallorca, el 71,5\% de las parejas no consulta la decisión con los familiares, y el $22,5 \%$ sí lo hacen.

\section{Los contactos con la Administración}

Las personas o parejas, una vez tomada la decisión de adoptar, inician los primeros contactos con los técnicos de las instituciones responsables de la protección de menores. Durante el período previo a la adopción, la mayoría de las familias de

\footnotetext{
${ }^{19}$ La suma total supera el $100 \%$ porque algunos niños reúnen varias de estas características a la vez.
} 
Tabla 4.

Persona de la que parte la idea de adoptar (porcentajes verticales)

\begin{tabular}{lccc}
\hline Idea de adoptar & CATALUÑA & MALLORCA & ANDALUCÍA \\
\hline De ambos padres & 64,0 & 55,0 & 19 \\
Del padre & 5,0 & 5,0 & 14 \\
De la madre & 29,5 & 38,7 & 60 \\
De otros & - & 1,2 & 7 \\
TOTALES & 100,0 & 100,0 & 93 \\
\hline
\end{tabular}

Fuente: Amorós (1987); March (1993); Palacios et al., (1997). Elaboración propia.

Cataluña y Mallorca suelen visitar una sola institución, pero en Cataluña, antes de adoptar, algunas familias visitaron hasta tres o más instituciones (el 35,9\%) (Tabla 5).

En general las familias valoran positivamente y están de acuerdo en que la Administración seleccione previamente las parejas que deseen adoptar, con el fin de proporcionar el mayor bienestar a los niños. Hasta seis veces se entrevistaron con la Administración el 18\% de las familias en Andalucía, pero lo más frecuente es tres o cuatro entrevistas. En Andalucía se estudia también el tiempo transcurrido entre la solicitud de la adopción y la primera entrevista, y entre ésta y la concesión del niño. El tiempo medio transcurrido para la primera entrevista fue de menos de un año para el 50\% de las familias, entre uno y dos años para el $29 \%$ y el resto esperaron más de dos años. Y el tiempo transcurrido entre la primera

Tabla 5.

Organismos visitados por las familias en el periodo previo de adopción (porcentajes verticales)

\begin{tabular}{lcc}
\hline$N^{\circ}$ de Organismos & CATALUNA & MALLORCA \\
\hline Uno & 45,6 & 68,7 \\
Dos & 18,4 & 10,0 \\
Tres o más & 35,9 & 10,0 \\
NS/NC & - & 11,2 \\
TOTALES & 100,0 & 100,0 \\
\hline
\end{tabular}

Fuente: Amorós (1987); March (1993). Elaboración propia. 
entrevista y la adopción, fue de menos de un año para la mitad de las familias y para un 24\% pasaron más de dos años (Palacios et al., 1997: 61). El tiempo que media entre el período de entrevistas y la adopción es vivido por las familias con "cierta intranquilidad e inseguridad" en Mallorca y Cataluña, y en Andalucía con "preocupación y temor".

La valoración por las familias de los técnicos de la Administración antes de la adopción suele ser bastante positiva. Pero después de la adopción los contactos con ellos apenas tienen lugar. Y los pocos que existen son porque, de antemano, ya estaban programados. En Andalucía estos encuentros posteriores tuvieron lugar por causas del seguimiento y control de la adopción (en el $32 \%$ de los casos) y por saludar y agradecer la concesión del hijo (el 20\%) (Palacios et al., 1997: 62). Aparte de las anteriores situaciones, las familias que adoptan no vuelven a consultar a los técnicos de la Administración. En Cataluña, cuando las familias observan problemas en los niños, en un $60,3 \%$ de los casos recurren a profesionales ajenos a la Administración. Y en Andalucía hacen lo mismo un $39 \%$ de los nuevos padres y sólo un 4\% recibió ayuda posterior de los equipos oficiales (Palacios et al., 1997:27). Este comportamiento parece explicarse más por el rechazo de las familias a que el niño vuelva a relacionarse con el ambiente del que salieron que por la no valoración de la capacidad de esos técnicos, pues en Andalucía (el $78 \%$ de las familias así lo expresaron) y, probablemente, en las otras autonomías, una mayoría se muestran satisfechos con su actuación en el transcurso de la demanda y concesión de la adopción.

\section{PERFIL DE LOS NIÑOS ADOPTADOS}

Presentados algunos rasgos de las familias adoptivas, veremos varias características de los niños adoptados. Primero las variables sexo, edad y aspectos sanitarios que más afectan a los niños en los primeros años de adopción. Y, en segundo lugar, dos rasgos dinámicos del proceso de adopción: el hecho de la "revelación" y el proceso de integración familiar y escolar.

\section{Sexo y edad de los niños adoptados}

Respecto al sexo, aunque no con grandes diferencias, se adoptaron más niñas en Cataluña y Mallorca y más niños en Andalucía (Tabla 6). Sin embargo, en Andalucía, aunque la mayoría de las familias dicen que se cumplieron sus preferencias de sexo en la adopción, a un $36 \%$ de ellas llegaron niños que no encajaban con sus deseos. Y de ese $36 \%$, la mayoría aceptó lo que las Instituciones le concedieron (en un $74 \%$ de casos).

Con relación a la edad, ninguna de las investigaciones coincide en los grupos de edad establecidos. Por lo tanto, resulta complejo realizar comparaciones. Pero 
hay un hecho evidente en las familias que adoptan: casi todas prefieren a niños menores de un año y muchas menos las que adoptan niños con cuatro o más años. Evidentemente la adaptación es mayor en edades más tempranas. Con menos de un año adoptaron niños un $44,7 \%$ de las familias en Cataluña, un $62,5 \%$ en Mallorca y un $61,8 \%$ en Andalucía. En esta última Comunidad, gran parte de los adoptados son recién nacidos (el $40,8 \%$ de los adoptados) y, en Cataluña, es donde más adopciones hay entre 5 y 8 años (tabla 7 ).

Tabla 6.

Sexo de los adoptados (porcentajes verticales).

\begin{tabular}{lccc}
\hline Sexo & CATALUÑA & MALLORCA & ANDALUCÍA \\
\hline Varón & 49,2 & 46,2 & 52,3 \\
Hembra & 50,8 & 53,7 & 47,7 \\
Total & 100,0 & 100,0 & 100,0 \\
\hline
\end{tabular}

Fuente: Amorós (1987); March (1993); Palacios et al., (1997). Elaboración propia.

Tabla 7.

Edad de los adoptados (porcentajes verticales).

\begin{tabular}{|c|c|c|c|c|c|}
\hline Edad & Cataluña & Edad & Mallorca & Edad & Andalucía \\
\hline $\begin{array}{l}\text { Menos de } 6 \\
\text { meses }\end{array}$ & 26,3 & Menos de 6 meses & 57,5 & Recién nacidos & 40,8 \\
\hline $\begin{array}{l}\text { De } 7 \text { a } 12 \\
\text { meses }\end{array}$ & 18,4 & De 7 a 12 meses & 5,0 & Menos de 1 año & 21,0 \\
\hline $\begin{array}{l}\text { De } 13 \text { meses a } \\
4 \text { años }\end{array}$ & 31,6 & De 2 a 3 años & 12,5 & De 1 a 2 años & 12,0 \\
\hline \multirow[t]{4}{*}{ De 5 a 8 años } & 23,7 & De 4 a 6 años & 16,2 & De 3 a 5 años & 9,0 \\
\hline & & De 6 a 9 años & 3,7 & De 6 a 9 años & 11,0 \\
\hline & & Más de 9 años & 2,5 & Más de 9 años & 5,0 \\
\hline & & $\mathrm{NS} / \mathrm{NC}$ & 2,6 & $\mathrm{NS} / \mathrm{NC}$ & 21,2 \\
\hline TOTAL & 100,0 & & 100,0 & & 100,0 \\
\hline
\end{tabular}

Fuente: Amorós (1987); March (1993); Palacios et al., (1997). Elaboración propia. 


\section{Problemas de los niños adoptados en el momento de la acogida}

Un aspecto bastante importante en la adopción es el análisis de los problemas que tienen los niños en el momento de la acogida. De ellos va a depender, en parte, la mejor o peor integración en el nuevo hogar. Primero veremos los problemas que presentan los niños al llegar a la familia y, posteriormente, el desarrollo que han seguido los mismos durante los primeros años.

Cataluña y Mallorca, si bien con porcentajes diferentes, coinciden en que la mayoría de los trastornos durante el primer año de acogida están relacionados con la salud, $47,3 \%$ y $12,5 \%$ respectivamente (tabla 8 ). En Cataluña, los niños del grupo de Guarda presentan siempre más problemas que los del grupo de Adopción. En el grupo de Adopción los problemas de salud más frecuentes tienen que ver con la desnutrición, el aparato respiratorio y digestivo. En el grupo de Guarda destacan los de desnutrición, infecciones, respiratorios, digestivos y los malos tratos físicos. Tras los problemas de salud, los trastornos emocionales y/o de conducta son los que más afloran (35,9\%). En el grupo de Adopción los problemas están relacionados con la hiperactividad, dificultades en el sueño y angustia ante la separación; y en el grupo de Guarda, con la enuresis, dificultades en el sueño, negativismo, desobediencia y rebeldía, hiperactividad e hipercinesia, angustia ante la separación y agresividad. Por último, los problemas que se dan en menor proporción son los de desarrollo, que ocurren en el $20,2 \%$ de los niños adoptados. Estos problemas tienen que ver con el lenguaje (vocabulario, pronunciación y estructuración) y con el retraso motor (falta de coordinación manual y en el caminar).

Tabla 8.

Presencia de trastornos en los adoptados en el momento de la acogida en cada comunidad (porcentajes horizontales).

\begin{tabular}{lccccccc}
\hline Tipología de & \multicolumn{3}{c}{ CATALUÑA } & \multicolumn{5}{c}{ MALLORCA } \\
\cline { 2 - 8 } Trastorno & $\mathrm{Si}$ & No & Total & $\mathrm{Si}$ & No & NS/NC & Total \\
\hline $\begin{array}{l}\text { Trastornos de } \\
\text { salud }\end{array}$ & 47,3 & 52,6 & 100,0 & 12,5 & 87,5 & 0,0 & 100,0 \\
$\begin{array}{l}\text { Trastornos de } \\
\text { desarrollo }\end{array}$ & 20,2 & 79,8 & 100,0 & 8,75 & 87,5 & 3,7 & 100,0 \\
$\begin{array}{l}\text { Trastornos de } \\
\text { conducta }\end{array}$ & 35,9 & 64,1 & 100,0 & 2,50 & 97,5 & 0,0 & 100,0 \\
\hline
\end{tabular}

Fuente: Amorós (1987); March (1993). Elaboración propia. 
En Mallorca, también son los problemas de salud los más comunes. Los más frecuentes, siguiendo este orden, son los relacionados con la desnutrición, alteraciones sensoriales, malos tratos físicos, problemas digestivos e infecciones o parásitos. En segundo lugar se sitúan los de desarrollo $(8,7 \%)$, relacionados con las alteraciones del lenguaje y del habla. Y los menos frecuentes son los problemas de conducta (2,5\%), relacionados con la hiperactividad, el sueño, la agresividad, rebeldía y la desobediencia.

Los problemas que las familias andaluzas encontraron en los hijos al incorporarse al hogar se distribuyeron de la siguiente forma: retraso en el desarrollo $(34,8 \%)$; problemas médicos $(28,7 \%)$; problemas de alimentación $(23,3 \%)$ y de sueño $(17,7 \%)$.

En todo el proceso de integración posterior a la acogida, la presencia y gravedad de los problemas en los niños están muy relacionadas con la estancia y el tiempo de permanencia en las instituciones, con los antecedentes de maltrato y con la pertenencia al grupo de adopciones especiales. Cuanto más tiempo han permanecido en los centros de acogida, normalmente suelen tener más problemas de conducta motivados por una socialización inadecuada. Lo mismo ocurre con los niños que tienen acumuladas experiencias de malos tratos y ausencia de afectividad. Esto es el motivo por el que la mayoría de las familias los prefieren menores de un año y, en muchas ocasiones, recién nacidos.

¿Cómo han evolucionado los problemas de los adoptados desde su acogida hasta el momento de realizar la investigación? Tanto en Cataluña como en Mallorca (en Mallorca la abstención en este aspecto es muy alta) se observa una evolución positiva de los trastornos de salud, de desarrollo y conducta, pues en el primer año de acogida, gran parte de los problemas habían desaparecido en ese período de tiempo (tabla 9).

Tabla 9.

Nivel de persistencia de los trastornos del adoptado (porcentajes verticales).

\begin{tabular}{|c|c|c|c|c|c|c|}
\hline \multirow{3}{*}{$\begin{array}{l}\text { Grado de } \\
\text { Pcrsistencia }\end{array}$} & \multicolumn{3}{|c|}{ CATALUÑA } & \multicolumn{3}{|c|}{ MALLORCA } \\
\hline & \multicolumn{3}{|c|}{ Tipo de trastornos } & \multicolumn{3}{|c|}{ Tipo de trastornos } \\
\hline & Salud & Desarrollo & Conducta & Salud & Desarrollo & Conducta \\
\hline No persisten & 57,4 & 26,1 & 43,9 & 21,2 & 18,7 & 22,5 \\
\hline Persist. Parcial & 35,2 & 26,1 & 43,9 & 6,2 & 3,7 & 6,2 \\
\hline Persist. Total & 7,40 & 47,8 & 12,2 & 1,2 & 1,2 & 0,0 \\
\hline $\mathrm{NS} / \mathrm{NC}$ & - & - & - & 70,0 & 76,2 & 71,2 \\
\hline TOTALES & 100,0 & 100,0 & 100,0 & 100,0 & 100,0 & 100,0 \\
\hline
\end{tabular}

Fuente: Amorós (1987); March (1993). Elaboración propia. 
R I S

REVISTA INTERNACIONAL DE SOCIOLOCIA

№ 33, Septiembre-Diciembre, 2002

PEDRO CASTION BOYER Y JOSÉ OCÓN DOMINGO

Las pocas familias que contestan en Mallorca confirman una evolución muy positiva en salud, desarrollo y conducta. Pero en Cataluña, donde contestan todas las familias encuestadas, la evolución es muy positiva en los problemas de salud y conducta y no tanto en problemas de desarrollo. Éstos últimos, en un $47,8 \%$ de los casos se mantienen, y si los sumamos a los casos en que los problemas persisten parcialmente, tenemos un 73,9\% de persistencia de los problemas de desarrollo en los niños adoptados en Cataluña. Esta mayor constancia de los trastornos de desarrollo (motricidad y lenguaje) se debe a que estos son problemas de mayor complejidad y, por tanto, requieren de una más frecuente y prolongada ayuda de especialistas.

\section{Integración familiar y escolar del adoptado}

La opinión de las familias en las tres investigaciones resulta muy positiva. Concretamente, en Cataluña, el 88,6\% de las familias valoran satisfactoriamente la integración familiar y sólo un 3,5\% la perciben insatisfactoriamente. Igualmente, para el $80,5 \%$, las relaciones con el resto de familiares son satisfactorias y sólo un 2,7 \% las califica como insatisfactorias. En Mallorca, el 98,7\% observan relaciones satisfactorias entre los padres y los adoptados, y el 93,7\% las que tienen lugar entre éstos y otras personas.

En Andalucía la integración familiar parece algo más intensa, pues para el $98 \%$ de los padres adoptivos sus hijos gozan de plena integración familiar. Pero, además, esta integración se ha producido muy pronto: para el 91\% ocurrió en los tres primeros meses de convivencia (Palacios et al., 1997: 73). Quizás fruto de esta rápida integración es el alto porcentaje de padres andaluces satisfechos con la adopción (el $90 \%$ ) y totalmente conformes con las características actuales de sus hijos (el 96\%). No obstante, conviene señalar que, en Andalucía, alrededor de un $20 \%$ de padres (sobre todo entre los padres de adopción especial) consideran que su vida transcurre con mayor dificultad desde la adopción. A pesar de todo, el 69\% que adoptaron hijos con características especiales confiesan sentirse satisfechos con la experiencia. (Palacios et al., 1997: 73-77).

Podemos decir que es pauta generalizada entre las familias un alto grado de satisfacción con los niños adoptados. Si en Andalucía la mayoría de ellos dicen sentirse contentos, en Mallorca un $88,7 \%$ de esas familias recomiendan adoptar a familiares y amigos. También es sorprendente el alto porcentaje de niños que siguen el nivel escolar que les corresponde. Así ocurre con los niños adoptados en Cataluña y Mallorca, donde más del $70 \%$ se encuentran en el nivel educativo adecuado a su edad (tabla 10). Lo mismo en Andalucía, pues el ajuste y rendimiento escolar es considerado como bueno y/o normal por un $85,6 \%$ de los padres, contra un $14,4 \%$ que opinan que sus hijos no marchan bien en la escuela (Palacios et al., 1997: 74).

Relacionado con el problema escolar, son interesantes los datos aportados por el estudio de Andalucía. Como ya indicamos anteriormente, únicamente la 
Tabla 10.

La escolarización actual del adoptado (porcentajes verticales).

\begin{tabular}{lcc}
\hline Nivel Escolar & MALLORCA & CATALUÑA \\
\hline Adecuado a su edad & 71,1 & 72,5 \\
Un año de retraso & 24,5 & 18,7 \\
Dos o más años & 4,4 & 6,2 \\
NS/NC & - & 2,5 \\
TOTAL & 100,0 & 100,0 \\
\hline
\end{tabular}

Fuente: Amorós (1987); March (1993). Elaboración propia.

investigación andaluza compara los niños adoptados con otros tres grupos de niños: con el grupo de sus compañeros actuales, con el grupo de niños del entorno de los adoptados que permanecieron en sus familias de origen y con el grupo formado por aquellos que ingresaron en una institución. Los resultados revelan que los niños adoptados presentan en la mayoría de las áreas investigadas, incluidas el rendimiento y la motivación escolar, puntuaciones más parecidas a sus compañeros actuales que a los niños de sus zonas de origen o a los niños que permanecen acogidos en una institución. Si tenemos en cuenta la dura realidad social vivida previamente por la mayoría de los adoptados, la similitud alcanzada por los mismos con los niños de su entorno tiene gran importancia, sobre todo cuando sabemos que un $38 \%$ del total de adoptados en Andalucía fueron considerados de adopción especial. Sin embargo, en la medición de la hiperactividad/distracción, los niños adoptados puntúan más alto que sus compañeros actuales de colegio. Esto ocurre, según los autores, porque los niños con experiencia previa de institucionalización prolongada y malos tratos constituyen un grupo numeroso entre los adoptados esos años y son, evidentemente, los que aumentan significativamente las estadísticas. Por el contrario, en autoestima y autoconcepto, los niños adoptados presentan puntuaciones promedio más elevadas (sobre todo los niños en edad preescolar). En contraste con los niños estudiados en los otros tres grupos, los niños institucionalizados son los que obtienen las peores puntuaciones en todas las dimensiones estudiadas: hostilidad/agresividad, hiperactividad/distracción, ansiedades y temores, conducta prosocial, etc. (Palacios et al., 1997: 115 y ss.).

Por la incidencia que el internamiento tiene en el desarrollo de la personalidad, según la información aportada por los padres, casi la mitad de los niños andaluces estudiados (un 48,8\%) habían estado en una o dos instituciones, un $32,6 \%$ no habian tenido esta experiencia en el $18,3 \%$ de casos no disponían de esta información. De los que estuvieron en alguna institución, el $41,9 \%$ permanecieron menos de un año, entre uno y tres años un $17 \%$ y más de cuatro años el $8,3 \%$ (un $31 \%$ de 
los padres de la muestra ignoraban el tiempo exacto que sus hijos habían estado institucionalizados). Con relación al maltrato, un 19,3\% de las familias conocían estas adversas experiencias sufridas por sus hijos, siendo estas situaciones más frecuentes en las niñas que en los niños (Palacios et al., 1997: 67-68).

\section{Aspectos relacionados con la "revelación"}

Con el término "revelación" se hace referencia al proceso que permite la información a la persona sobre su condición de adoptada. Esta información incluye dos aspectos: la información sobre los propios antecedentes y orígenes, y el hecho mismo de ser adoptado. Para ofrecer una visión más completa de cómo los padres adoptivos abordan esta cuestión, recogemos, en primer lugar, el grado de conocimiento que los padres adoptivos tienen sobre el historial de sus hijos y, en segundo lugar, otros aspectos implicados en la información sobre la misma condición adoptiva (proceso que también hace referencia, en mayor o menor medida, a cuestiones sobre los orígenes).

En líneas generales, en las tres investigaciones se señala que la información que los padres tienen sobre la anterior vida del niño es nula o bastante escasa. Las investigaciones de Cataluña y Mallorca ponen de relieve que existe un escaso conocimiento de las particularidades del historial de sus hijos. Más del $70 \%$ de los padres adoptivos, tanto en Cataluña como en Mallorca, no conocen nada o tienen poca información sobre sus hijos (tabla 11).

Esta escasez de información está relacionada con la política de las instituciones por mantener estos datos reservados en los archivos, facilitando mayor información sólo en los casos en que les es solicitada y, también, con el poco interés de

Tabla 11.

Nivel de conocimiento por los padres de los origenes del adoptado (porcentajes verticales).

\begin{tabular}{lcc}
\hline Conocimiento & CATALUÑA & MALLORCA \\
\hline Bastante & 25,4 & 26,2 \\
Poco & 28,9 & 30,0 \\
Nada & 45,6 & 41,2 \\
NS/NC & - & 2,5 \\
TOTALES & 100,0 & 100,0 \\
\hline
\end{tabular}

Fuente: Amorós (1987); March (1993). Elaboración propia. 
los padres en conocer el pasado de sus hijos. Por ello, el $75 \%$ de los padres en Cataluña y el $88,7 \%$ en Mallorca no desean tener más información sobre la vida de los niños. No conociéndola, dicen los padres en Cataluña y Mallorca, están libres del deber de comunicársela algún día y de la responsabilidad de la guarda del secreto (Amorós, 1987: 170-171; March, 1993: 71-72).

Y si los padres no tienen mucho interés en conocer el pasado de sus hijos, sí son favorables a que conozcan sus orígenes biológicos cuando lleguen a la mayoría de edad: un $81,2 \%$ son de esta opinión en Mallorca y, en Cataluña, un $44 \%$ de los padres del grupo de Adopción y un $24 \%$ del grupo de Guarda (Amorós, 1987: 175; March, 1993: 72). En Andalucía las opiniones están divididas, pues un $50 \%$ de los padres se mostraron a favor y un $50 \%$ en contra de que el niño conozca datos sobre sus padres biológicos (Palacios et al., 1997: 78). Quizás por ello, un $18 \%$ desconocen si sus hijos han estado institucionalizados y, en el cašo de haberlo estado, el $31,3 \%$ de los padres no saben el tiempo que permanecieron en el centro. Tampoco recibieron información sobre la familia biológica del niño el 62,5\% de los padres (Palacios et al., 1997: 63-64).

Con relación a la información de la condición de adoptado, en Cataluña el $90 \%$ de los niños ya había sido informados del tema por los propios padres. En Mallorca un 72,5\% de los niños ya conocían que eran adoptados cuando fueron a su nuevo hogar. Y en Andalucía es donde menos la conocían, un 52,4 \%, pero el resto de padres pensaban decírselo a medida que los viesen psicológicamente más preparados y maduros. En Cataluña y en Mallorca la revelación tiene lugar, generalmente, entre los tres y cinco años (tabla 12). Son muy pocos los padres que comunican al hijo la condición de adoptado a partir de los nueve años. Los

Tabla 12.

Edad del niñola cuando se procedió a la revelación (porcentajes verticales)

\begin{tabular}{lcc|lc}
\hline EDAD & CATALUÑA & MALLORCA & \multicolumn{1}{|c}{ EDAD } & ANDALUCÍA \\
\hline Menos de 3 años & 33,3 & 6,2 & Antes de los 4 años & 46,9 \\
Entre 3 y 5 años & 40,2 & 36,2 & De 4 a 6 años & 30,1 \\
Entre 6 y 8 años & 20,8 & 22,5 & De 6 a 9 & 16,8 \\
Entre 9 y 12 años & 5,5 & 8,7 & Mayores de 9 años & 6,2 \\
Más de 12 años & - & 2,5 & - & - \\
NS/NC & - & 23,7 & - & - \\
TOTAL & 100,0 & 100,0 & TOTAL Andalucía & 100,0 \\
\hline
\end{tabular}

Fuente: Amorós (1987); March (1993); Palacios et al., (1997). Elaboración propia. 
RIS

REVISTA INTERNACIONAL DE SOCIOLOGIA

N* 33, Septiembre-liciembre, 2002

PEDRO CASTÓN BOYER y JOSÉ OCÓN DOMINGO

intervalos de edad en el estudio de Andalucía son diferentes. La mayor parte de estos padres hacen la revelación antes de los cuatro años (46,9\%), siendo muy pocos los que la hacen cuando tienen nueve o más años.

La revelación produce dudas e incertidumbres en las familias. Es un tema que crea tensión, sobre todo antes de comunicárselo. Los tres estudios hablan de este período de tiempo como un tiempo de temores. En Cataluña, aunque la mayoría de los padres dicen sentirse tranquilos (64\%), sin embargo hay un $27 \%$ que sintieron preocupación e inseguridad respecto a la forma más adecuada de hacerlo, y un $9 \%$ preocupados por las reacciones de los niños al conocer su situación. En Mallorca fueron menos los padres que se sintieron tranquilos en ese momento $(22,3 \%)$, pero un $20 \%$ temieron por la reacción del niño y un $3,7 \%$ sintieron un gran temor. Las familias andaluzas fueron más precavidas, un $61,5 \%$ de ellas procuraron prepararse para ese momento, bien hablando frecuentemente antes entre ellos (41,9\%), consultando libros o yendo a un profesional $(19,6 \%)$.

La reacción de los niños al conocer su condición de adoptado contrasta con el temor de algunos padres. En Cataluña el $78 \%$ reaccionó con naturalidad (sobre todo aquellos que recibieron la información gradualmente), un $14 \%$ no quiso asumir la situación, no creyéndola o negándola, y un $8 \%$ tuvo reacciones de sorpresa y preocupación. En Mallorca, en un 53,7\% de los casos la reacción de los niños es calificada de natural, con sorpresa y preocupación en un 7,5\% y sólo un $6,2 \%$ no quiso asumir la situación. $Y$ en Andalucía las reacciones fueron positivas en un $70 \%$ de los casos, de indiferencia en un $16 \%$ y negativas en un $14 \%$ de los niños. Además, un $70 \%$ de padres apuntan que sus hijos hablaban de este tema con naturalidad y, muy pocos niños, rechazan hacerlo (16\%). En este último grupo se encuentran los niños de adopción múltiple, los adoptados con más de seis años y los que permanecieron en una institución más de un año.

En un orden práctico, quizás uno de los aspectos de acción más complicados para las familias sea cómo y quién afronta el tema de la adopción con el hijo. Respecto al cómo, en Cataluña la mayoría de los padres utilizaron la propia historia del niño (hablándole de su pasado), le siguen los que se apoyaron en una narración (aprovechando un cuento o una historia) y los que aprovecharon las preguntas de información de sus hijos sobre el nacimiento de los niños. Este último es el medio más utilizado por los padres en Mallorca (un 35\% de casos), otros aprovecharon una la oportunidad $(16,2 \%)$ y, menos, con ocasión de un programa de televisión (6,2\%). En Andalucía, muchos padres opinaron que del tema de la adopción no conviene hablar mucho con los hijos. Por ello, quizás, casi la mitad (el 46,8\%) piensa que los niños han de olvidar totalmente su pasado, o que sólo una vez se debe explicar al niño su condición de adoptado (el 30,6\%). El cuento es el recurso más utilizado por los padres andaluces y esperan a que la iniciativa la tome el hijo (Palacios et al., 1997: 78-79).

En el quién, son mayoritariamente las madres a las que se les encomienda esta tarea. Como en otros aspectos, se sigue un modelo tradicional de reparto de 
papeles según el género. En Cataluña un 50\%, en Andalucía un 48\% y en Mallorca un $43,7 \%$ de madres informaron a los hijos sobre su condición de adoptado. Conjuntamente, ambos padres a la vez, en Cataluña lo hicieron un $40 \%$, un $42 \%$ en Andalucía y un 21,2\% en Mallorca. En Cataluña un 10\% lo hicieron entre el padre y los compañeros de colegio. En Andalucía ningún padre solo abordó este tema con los hijos, y en Mallorca lo hizo un 2,5\% .

El temor a la revelación, aunque no todas las familias lo sintieron, parece manifestarse en ese $10 \%$ de padres que se repartieron la tarea con los compañeros de colegio en Cataluña; en el 2,2\% de casos de Mallorca, donde los padres acudieron a otras personas.y, quizás, en ese $34,2 \%$ de familias andaluzas que esperaron a que los hijos tomasen la iniciativa. Igualmente, otro indicador de ese temor puede ser el hecho de que muchos padres no digan nada de la adopción en el colegio de los hijos. Por lo menos en Cataluña hay un 78\% del grupo de adopción y un $88 \%$ del grupo de Guarda que no había comunicado estas circunstancias a la escuela. En Mallorca, un 16,3\% de padres no lo habían dicho y, en Andalucía, un 15,3\% tampoco lo había hecho.

\section{CONCLUSIONES}

Hemos mostrado los rasgos más sobresalientes que acompañan la puesta en práctica de la adopción de menores en España, muy similar a la existente en los países de nuestro entorno. La aprobación de nuestra Constitución y la instauración del Estado democrático constituyen, hasta el momento, la culminación de la evolución histórica respecto a esta medida, que ha dado lugar a una nueva y más moderna forma de concebir la marginación y los derechos de la infancia.

La adopción (junto al acogimiento familiar) constituye en la actualidad una alternativa social válida para aquel grupo de menores que, por circunstancias especiales, estaría abocado a permanecer hasta la mayoría de edad internado en instituciones. No obstante, las investigaciones advierten sobre las repercusiones de la adopción tanto en la dinámica de la familia como en los hijos adoptados. Hoy queda controlado por las entidades públicas de la Administración encargadas de la protección de menores, con el fin de evitar beneficios económicos de particulares y perjuicios a los niños adoptados.

Actualmente, no se concibe la adopción como un recurso destinado sólo a familias de un determinado nivel socio-económico-cultural o estabilidad matrimonial, sino que, siempre en beneficio del menor, los técnicos responsables de la selección otorgan también mucha importancia a factores relacionados con la motivación, aceptación de las características del niño, disposición para la revelación, habilidades educativas, capacidad de acogida, madurez psicológica de la pareja, etc. 
RIS

REVISTA INTERNACIONAL DE SOCIOLOCIA

№ 33, Septiembre-Diciembre, 2002

PEDRO CASTÓN BOYER Y JOSÉ OCÓN DOMINGO

El derecho del niño a conocer sobre su condición de adoptado, sobre su pasado y orígenes, así como la mejor forma de transmitirle esta información, ha hecho que los técnicos de protección otorguen capital importancia a este factor durante todo el proceso de formación y selección de familias. Podemos decir, por consiguiente, que prácticamente se ha erradicado el silencio que hasta fechas recientes acompañaba al hecho adoptivo.

Constituye un hecho la disminución de niños disponibles para una adopción nacional, debido, básicamente, al menor número de niños abandonados y mayor eficacia de las políticas de protección social, a una generalización de los métodos anticonceptivos e incremento del aborto, a la mayor tolerancia social respecto a las madres solteras y al escaso número de nacimientos, que han convertido a España en el país con la tasa de natalidad más baja del mundo. Se observa también un incremento de niños susceptibles de una adopción especial y del número de demandas para proceder a su adopción.

La formalización de adopciones nacionales en la última década (1990-1999) se ha mantenido estable. En casi una década el número de adopciones ha mantenido un crecimiento sostenido. Según los últimos datos oficiales, la dinámica seguida por el recurso hasta el año 1999 ha fluctuado poco, no alcanzando ninguno de estos años el millar de formalizaciones, a excepción de 1996 donde se produjeron 1.025 adopciones. Por cada 100.000 habitantes, la tasa de adopciones nacionales de 1999 respecto a 1990 ha subido casi tres puntos. Las CC.AA. que han experimentado una mayor tasa de crecimiento han sido Murcia, Baleares y Valencia, todas ellas en el próspero arco mediterráneo. La tasa de Murcia ha pasado de ser en 1990 de 5,1 adopciones por 100.000 habitantes a 26,6 adopciones en 1999; la de Baleares de 1,1 en 1990 a 20,9 en 1999 y la de Valencia de 2,4 pasa a 11,6. $\mathrm{Y}$ las CC.AA. con un mayor descenso en las tasas de adopción han sido CeutaMelilla (-30,9 adopciones en 1999 respecto a 1990) y Aragón (-9,7 adopciones en 1999 respecto a 1990).

Bastantes de las razones antes expuestas (menos niños disponibles de adopción en España y, en ocasiones, las muchas trabas administrativas) han podido contribuir al espectacular aumento experimentado por la adopción internacional (en el 2.000 el $78 \%$ de las adopciones en España lo fueron de niños extranjeros), y la consiguiente preocupación por evitar el tráfico de niños a través de una serie de mecanismos internacionales y la intervención de las Entidades Colaboradoras de Adopción Internacional. No contamos aún en España con, investigaciones que permitan conocer cómo afecta esta modalidad de adopción al desarrollo de la personalidad de los niños extranjeros y cómo se produce el ajuste familiar. Sin embargo, el número de adopciones internacionales muestra un importante y progresivo aumento, superando de forma perceptible a la adopción nacional, pues, si en el año 1997 se formalizó la adopción de 883 niños/as nacionales, los de origen internacional llegan a la cifra de 942. Esta tendencia ascendente de las adopciones internacionales es claramente perceptible a partir de 1997, pues 
en 1998 se formalizan 1.482, en 1999 son ya 2.006 y, finalmente, en el 2000 se alcanzan 3.062 adopciones ${ }^{20}$. Es decir, que mientras que el número de adopciones nacionales ha permanecido bastante estable en esta década, el arrojado por las adopciones internacionales se ha triplicado en los dos últimos años.

Como hemos podido observar, repasando las escasas investigaciones españolas sobre la adopción, en general, ésta se ha convertido en un buen recurso para los niños y las familias adoptantes. Esta capacidad se demuestra, sobre todo, cuando los adoptados son comparados con los niños acogidos en centros, que son siempre los que, en las distintas áreas estudiadas, obtienen los peores resultados: hostilidad y agresividad, ansiedad y temores, hiperactividad, distracción, poca autoestima, bajo rendimiento escolar, y en problemas y malestares psicosomáticos. Por ello, en España, en torno a los años setenta, se aborda con detenimiento el estudio de estas clásicas estructuras, bajo una filosofia desinstitucionalizadora (Casas, 1995), para acomodarla a aquella más avanzada de los países vecinos. La promulgación de la Constitución Española de 1978 acelera todo el proceso, primando, frente a los internamientos, medidas más normalizadas de tipo preventivo económico y social, así como el acogimiento familiar y la adopción. La eficacia de estos enfoques es claramente perceptible si comparamos el número de menores bajo acogimiento residencial en España en 1989, que ascendía a 24.406, con los acogidos familiarmente, que sólo sumaban 2.913 (Defensor del Pueblo Español, 1991). Diez años después estas cifras se han equilibrado, pasando a ser los niños en acogimiento residencial 13.370 y 11.529 en acogimiento familiar (Defensor del Pueblo Andaluz, 1999), como resultado de los nuevos métodos psicopedagógicos que aconsejan el familiar.

El futuro de la adopción en España está abierto a los cambios que se están produciendo en las sociedades modernas. He aquí algunos de los temas pendientes. Hay un debate abierto sobre la conveniencia y consecuencias de la llamada "adopción abierta", que permitiría el contacto entre la familia biológica y la adoptiva. Además del fuerte crecimiento de las adopciones internacionales, motivado por la escasez de niños normales en disposición de adoptar, falta en nuestro país una legislación sobre la adopción de personas mayores (solicitud que ya se ha producido con una anciana en Cataluña); sobre la adopción por parejas homosexuales ${ }^{21}$;

\footnotetext{
${ }^{20}$ Datos proporcionados directamente por $\mathrm{D}^{\mathrm{a}} \mathrm{M}$. Jesús Montané, responsable actualmente del Servicio de Adopción y Protección de Menores (Ministerio de Trabajo y Asuntos Sociales), a quien mostramos nuestro más sincero agradecimiento.

${ }^{21} \mathrm{La}$ Comunidad de Navarra constituye una excepción en España, habiendo reconocido la igualdad de derechos a las parejas heterosexuales y homosexuales, incluida la adopción, por Ley Foral 6/2000, de 3 de julio, "para la igualdad jurídica de las parejas estables". No obstante, esta Norma ha sido recurrida al Tribunal por el Gobierno al entender que en materia de matrimonio la capacidad para legislar corresponde al Estado. Con este mismo contenido se acaba de aprobar una ley en el País Vasco.
} 
RIS

REVISTA INTERNACIONAL DE SOCIOLOCIA

$N^{*} 33$, Septiembre-Diciembre, 2002

PEDRO CASTÓN BOYER Y JOSÉ OCÓN DOMINGO

sobre la solicitud de guarda de potestad o tutela de los hijos a Asuntos Sociales por la pérdida de control de los padres sobre ellos, que en ocasiones llegan a propiciarles agresiones físicas y psicológicas de una forma repetida; y sobre el reconocimiento de la filiación producida en los nacimientos de niños nacidos de "madres de alquiler", con óvulos y esperma de donantes familiares o no que voluntariamente desean este tipo de reproducción biológica, dando lugar a una gama muy variada de modelos de filiaciones.

Finalmente, conviene recordar algunas de las repercusiones que la adopción puede tener en la estructura familiar tradicional. Puede influir en un aumento de las familias monoparentales; podrían aumentar los hogares de personas mayores con hijos; permitiría, en caso de legalizarse en España, a los hogares formados por dos hombres o dos mujeres llegar a ser núcleos familiares con hijos; y para evitar posibles matrimonios de los adoptados con algún hermano/a u otrö pariente biológico desconocido, y ayudar al buen desarrollo de la personalidad, la "revelación", el conocimiento de sus antecedentes por parte del adoptivo, será muy conveniente en el futuro, sobre todo por el cada vez mayor número de familias con hijos adoptivos.

\section{BIBLIOGRAFÍA}

ÁLVAREZ SANTALÓ, L. C. (1980), Marginación social y mentalidad en Andalucia Occidental. Expósitos en Sevilla (1813 - 1910), Consejería de Cultura de la Junta de Andalucía, Sevilla.

ÁlVAREZ VÉLEZ, M.A. y E. CALVO BLANCO (1998), Derechos del Niño, MacGraw Hill, Madrid.

AMORÓS, P. (1986), La adopción desde una perspectiva socioeducativa. Aspectos psicosociales y educativos, Departamento de Pedagogía experimental, terapéutica y Orientación. Facultad de Filosofía y Ciencias de la Educación (tesis doctoral), Barcelona.

(1987), La adopción y el acogimiento familiar, Narcea, Barcelona.

ARIÈS, PH. (1987), El niño y la vida familiar en el Antiguo Régimen, Taurus, Madrid.

AUDUSSEAU-POUCHARD, M. (1997), Adoptar un hijo hoy, Planeta, Barcelona.

BOWLBY, J. (1951), Maternal Care and Mental Healt, H.W.O., Ginebra.

BORDERIES-GUEREÑA, J. (1996), "Niños y niñas en familia", en J.M. Borrás Llop (dir.), Historia de la infancia en la España Contemporánea 1834-1936, Ministerio de Trabajo y Asuntos Sociales y Fundación Germán Sánchez Ruipérez, Madrid.

CARMONA GARCÍA, J. I. (1988), "La asistencia social en la España de los austrias", en VV.AA. De la beneficencia al bienestar social, Siglo XXI, Madrid. 
CASAS, F. (1995), "España", en La Atención a la infancia en la Unión Europea. Guia por paises sobre acogimiento familiar y atención residencial, Ministerio de Asuntos Sociales, Madrid, pp. 223-239.

CESPEDES MAC-CROHON, M. de. (1950), "El problema de la adopción y sus fases en España", Revista de la Obra de Protección de Menores, núm. 23, pp. 19-25.

CHAVANNEAU DE GORE, S. (1992), “Adopción: un silencio en la historia”, en E. Giberti y S. Chavanneau de Gore (coord.), Adopción y Silencios, Sudamericana, Buenos Aires.

CHEMIN, B. (1974), “Aperçus socio-juridiques sur l'Adoption”, Bourdeaux Médicale, núm. 5, pp. 439-446.

CONVENCIÓN DE LAS NACIONES UNIDAS SOBRE LOS DERECHOS DEL NIÑO, de 20 de noviembre de 1989 (ratificación en B.O.E. Núm. 313, de 31 de diciembre).

CONVENIO RELATIVO A LA PROTECCIÓN DEL NIÑO Y A LA COOPERACIÓN EN MATERIA DE ADOPCIÓN INTERNACIONAL, La Haya, 1993 (en vigor en España desde 1 de noviembre de 1995; B.O.E. de 1 de agosto).

CONVENCIÓN DE LAS NACIONES UNIDAS DE 20 DE NOVIEMBRE DE 1989, SOBRE LOS DERECHOS DEL NIÑO.

DEFENSOR DEL PUEBLO ESPAÑOL (1991), Estudio sobre la situación del menor en centros asistenciales de internamiento y recomendaciones sobre el ejercicio de las funciones protectora y reformadora, Oficina del Defensor del Pueblo, Madrid.

DEFENSOR DEL PUEBLO ANDALUZ (1999), El Sistema de Protección de Menores (3 vols.), Oficina del Defensor del Pueblo, Sevilla.

GUERRERO SERÓN, A. (1996), Manual de Sociologia de la Educación, Síntesis, Madrid.

DE MAUSE, Ll. (1982), Historia de la infancia, Alianza, Madrid.

GOFFMAN, E. (1961), Asylums, Cox \& Wyman, Gran Bretaña [Edición en castellano Internados, Amorrortu, Buenos Aires, 1988].

HUALDE, J. (1979), La adopción del propio hijo natural reconocido, Aranzadi, Pamplona.

IGLESIAS DE USSEL, J. (1983), Infancia y Sociedad en España, Hesperia, Jaén.

(1984), "La relación entre infancia y familia en España", Revista Española de Investigaciones Sociológicas, $\mathrm{n}^{\circ} 27$, pp. 7-39.

KADUSHIN, A. (1980), Child Welfare Services, McMillan, Nueva York.

LEY 21/1987, DE 11 DE NOVIEMBRE, POR LA QUE SE MODIFICAN DETERMINADOS ARTÍCULOS DEL CÓDIGO CIVIL Y DE LA LEY DE ENJUICIAMIENTO CIVIL EN MATERIA DE ADOPCIÓN (B.O.E. núm. 275, de 17 de noviembre). 


\section{RIS}

LEY ORGÁNICA 1/1996, DE 15 DE ENERO, DE PROTECCIÓN JURÍDICA DEL MENOR, DE MODIFICACIÓN PARCIAL DEL CÓDIGO CIVIL Y DE LA LEY DE ENJUICIAMIENTO CIVIL (B.O.E. núm. 15, de 17 de enero).

LEY 18/1999, DE 18 DE MAYO, DE MODIFICACIÓN DEL ARTÍCULO 9, APARTADO 5, DEL CÓDIGO CIVIL (B.O.E. núm. 119, de 19 de mayo).

LÓPEZ MÉNDEZ, E. (1995), "La política social con la infancia", en Gualda Vargas et al., (coords.). Avances en Politica Social, Diputación Provincial, Granada.

MANAÏ, D. (1990), "La dispense de consentement en matière d'adoption: autonomie individuelle et contrôle social", Déviance et societé, núm. 3, pp. 275-294.

MARCH CERDÁ, M. X. (1993), La adopción en Mallorca. Una investigación evaluativa, Universidad de las Islas Baleares, Consejería de Gobernación y Dirección General de Juventud, Menor y Familia, Palma de Mallorca.

MORENO GONZÁLEZ, A. (1988), "Hacia la felicidad pública por la Cienca y la Educación", Revista de Educación, núm. Extraordinario, pp. 393-419.

OCÓN DOMINGO, J. (1995), "La situación social de la infancia durante la Edad Media", en M.T. Vega y M.C.Tabernero (comps.), Psicologia social de la educación y de la cultura, Eudema, Salamanca.

PADILLA PIÑOL, M. (1988), Guia juridica de la adopción, Barcelona, Fausí, Barcelona.

PALACIOS, J., Y. SANCHEZ y E.M. SANCHEZ (1997), La adopción en Andalucia, Consejería de Asuntos Sociales, Dirección General de Atención al Niño, Sevilla.

RESOLUCIÓN DEL CONSEJO DE EUROPA (77) 33 SOBRE EL ACOGIMIENTO DE MENORES, de 3 de noviembre de 1977.

RODRIGUES, A. (1997), “A adopçao: um antes; e depois?”, Infancia e Juventude, núm. 2, pp. $31-70$.

ROZEMBLUM DE HOROWITZ, S. (1990), Adoptar: lo legal, lo psicológico, lo social, Kargieman, Buenos Aires.

RUBINO, R. (1995), “L'adozione in Spagna”, Diritto, famigli e persone, núm. 2, pp. 843-873.

RUIZ BERRIO, J. (1988), "La educación del pueblo español en el proyecto de los ilustrados", Revista de Educación, núm. Extraordinario, pp. 163-191.

SPITZ, R. (1945), "Hospitalism: an inquiry into the genesis of psychiatric conditions in early childhood", Psychoanalytic Study of the child, núm. 1, pp. 153-172.

SERRANO GARCÍA, I. (1997), "La adopción según las Leyes 21/1987 de 11 de noviembre y 1/1996, de 15 de enero", en I. Serrano García (coord.), La protección juridica del menor, Junta de Castilla y León, Consejería de Sanidad y Bienestar Social. 
SUBDIRECCIÓN GENERAL DE PROGRAMAS DE SERVICIOS SOCIALES (1998), Estadistica básica de protección a la infancia, Dirección General de Acción Social, del Menor y de la Familia, Ministerio de Trabajo y Asuntos Sociales, Madrid.

(1999), Estadistica básica de protección a la infancia, Dirección General de Acción Social, del Menor y de la Familia, Ministerio de Trabajo y Asuntos Sociales, Madrid.

VARELA, J. y M. ALVAREZ- URÍA (1991), Arqueología de la escuela, Ediciones de La Piqueta. 